\title{
¿Cómo genera valor el emprendimiento social de inclusión socio-laboral? Propuesta metodológica para la identificación y análisis de buenas prácticas
}

\author{
Lina María Murillo Pérez ${ }^{1}$
}

Recibido: 18 de noviembre de 2020 / Aceptado: 10 de noviembre de 2021 / Publicado: 4 de enero de 2022

\begin{abstract}
Resumen. Todo emprendimiento social tiene como principal fin la creación de valor social, o lo que significa, la generación de cambios positivos en la calidad de vida de las personas y comunidades a las cuales dirige su servicio o intervención. Es imperante, para los gestores de estas organizaciones, conocer los medios y formas por las cuales se crea valor en los diferentes stakeholders, para así, establecer las estrategias apropiadas que posibiliten la maximización de dicho impacto. El objetivo de este trabajo es diseñar una metodología que permita identificar y analizar las acciones, procesos y modelos de operación adoptados por un emprendimiento de inclusión socio-laboral para generar valor en sus principales grupos de interés. La metodología resultante pretende, además, facilitar el reconocimiento de aquellas "buenas prácticas" susceptibles de ser adoptadas por organizaciones de objetivo similar, que contribuyan a incrementar su impacto en las comunidades donde operan. Para la construcción metodológica se analizó el aporte de diversos enfoques organizacionales y de desempeño social, entre otros, la teoría de stakeholders, el mapa estratégico, el enfoque de valor compartido y reconocidos estándares de Responsabilidad Social Empresarial. Asimismo, se retomó elementos de la planificación estratégica de dos organizaciones que trabajan en el campo del empleo inclusivo. Como producto final, se propone entonces el diseño de un estudio de caso, el cual es actualmente aplicado en dos emprendimientos sociales valencianos que tienen como misión la inclusión socio-laboral de colectivos en riesgo de exclusión.
\end{abstract}

Palabras clave: Valor Social; Inclusión socio-laboral; Grupos de interés; Impacto social; Mapa estratégico; Estudio de caso.

Claves Econlit: A13, L31, M14, B55.

\section{[en] ¿How does social-labor inclusion entrepreneurship generate value? Methodological proposal to identify and analyze good practices}

\begin{abstract}
The main purpose of all social entrepreneurship is creating social value, or what it means, to generate positive changes in the quality of life of the people or communities for which they work. It is imperative, for the managers of these organizations to know the means and ways through which value is created in the different stakeholders in order to establish the proper strategies to maximize this impact. The objective of this work is to design a methodology that allows to identify and analyze the actions, processes and operation models adopted by a social-labor inclusion entrepreneurship to generate value in its most important stakeholders. The resulting methodology also tries to facilitate the recognition of "good practices" susceptible to be replicated by other organizations with similar objectives, which contribute to increasing their impact in the communities where they operate. For the methodological construction, the contributions of diverse organizational and social performance approaches were analyzed, among others, the stakeholder theory, the strategic map, the shared value proposition and recognized standards of Corporate Social Responsibility. Likewise, some elements of the strategic planning of two social organizations that work in the field of inclusive employment were considered. As a final product, the design of a study case was proposed, which is currently being applied in two Valencian social entrepreneurships whose mission is the social-labor inclusion of groups at risk of exclusion.
\end{abstract}

Keywords: Social value; Social impact; Socio-labor inclusion; Stakeholders; Strategic map; Case study.

Sumario. 1. Introducción. 2. Marco conceptual. 3. Construcción de la metodología. 4. Resultados: estudio de caso para el análisis de las "buenas prácticas" de gestión organizacional que potencian la generación de valor social en los diferentes grupos de interés. 5. Reflexiones finales y conclusiones. 6. Referencias bibliográficas.

Cómo citar. Murillo Pérez, L.M. (2022) ¿Cómo genera valor el emprendimiento social de inclusión socio-laboral? Propuesta metodológica para la identificación y análisis de buenas prácticas. REVESCO. Revista de Estudios Cooperativos, vol. 140 , e78927. https://dx.doi.org/10.5209/reve.78927. 


\section{Introducción}

La creación de valor social se constituye en la principal característica misional de cualquier emprendimiento social. En este tipo de proyectos u organizaciones, independientemente de cuál sea la figura jurídica que los conforme o los rija, siempre deberá predominar los objetivos sociales sobre los económicos. El valor social tiene diversas formas de manifestarse en los emprendimientos, entre otras: promoviendo la inclusión social, satisfaciendo una necesidad social no atendida por el Estado, generando empleo estable, trabajando respetuosamente con el medio ambiente o enfocándose en incitativas que contribuyan a la cohesión social y al desarrollo territorial (Sánchez Espada, Martín López, Bel Durán, \& Lejarriaga Pérez de las Vacas, 2018).

Debido a esta variedad de manifestaciones, son múltiples los sectores y actividades dentro del espectro del emprendimiento social. Mientras que en los países menos desarrollados, los emprendimientos se centran en proveer servicios sociales básicos a las comunidades menos favorecidas, en las economías más avanzadas resaltan otro tipo de intervenciones como la protección del medio ambiente, el fomento de la cultura y el apoyo a las personas discapacitadas (Curto, 2012). En el caso europeo, se ha identificado que la actividad más visible de las empresas sociales (y una de las más dominantes) es la integración laboral de grupos en riesgo de exclusión (European Commission, 2014). De acuerdo a Defourny y Nyssens (2008), la lucha contra el desempleo y el fomento del crecimiento del empleo, se constituyen en un campo de acción clave para las empresas sociales europeas; esto, como respuesta a la necesidad de políticas de integración laboral más activas e innovadoras y a las persistentes altas tasas de desempleo en colectivos vulnerables.

Existen diversos obstáculos que limitan la participación de estos grupos en la vida social, política y económica del territorio que habitan, y los cuales no se refieren únicamente a un problema "material" (Rubio, 2006). Es decir, dichos limitantes pueden provenir desde la misma sociedad, revelados en forma de prejuicios, estereotipos y subvaloración de las capacidades de los individuos, o bien, de dificultades propias de las personas como la falta de formación y cualificación, las escasas redes sociales, la poca experiencia y otros condicionamientos físico-funcionales.

Es así que los emprendimientos sociales que trabajan en pro de la integración socio-laboral, buscan reducir algunos de estos factores limitantes por medio de diversas prácticas y servicios como: la formación y cualificación para el trabajo; los itinerarios de inserción y la intermediación laboral, entre otros. Cualquiera que sea la estrategia o modelo de operación, el reto de los emprendimientos es el mismo: maximizar el valor social para los colectivos atendidos y demás grupos de interés. Es prioridad entonces, de sus gestores y administradores, conocer los medios y formas que permiten a la organización o proyecto, crear valor en los diferentes stakeholders. Este conocimiento se vuelve perentorio a la hora de establecer estrategias de gestión efectivas, pues fortalece la capacidad del emprendimiento para asignar recursos en las actividades críticas que influyen mayormente en la creación de valor social.

Sin embargo, establecer y comprender dichas rutas y procesos puede ser tarea compleja, principalmente porque el valor social es un concepto subjetivo y será diferente para personas diferentes en situaciones diferentes (J. Nicholls et al., 2012); los beneficios percibidos (impacto) varían en función de las experiencias particulares de cada individuo o grupo. Por consiguiente, como lo plantea Mulgan (2010), se requieren marcos y herramientas robustas y flexibles para la gestión del valor social que: a) reconozcan que este tipo de valor no es algo objetivo y estable; b) sean de utilidad tanto para la toma de decisiones como para la evaluación y c) que más allá de las métricas, propicien espacios participativos de análisis y discusión generando reflexión sobre lo que realmente crea valor.

Con todo esto, los gestores de los emprendimientos sociales deben esforzarse por encontrar, adaptar o diseñar metodologías efectivas que les facilite conocer y gestionar el valor social creado por medio de sus acciones. Cualquier instrumento que se defina como método de estudio y análisis del valor social, deberá considerar las particularidades de la organización y proponer, además, técnicas cualitativas para una adecuada identificación y entendimiento de las demandas, expectativas y percepciones de los diferentes grupos de interés.

En atención a estas necesidades, el presente trabajo tiene como objetivo diseñar una metodología que permita identificar y analizar los procesos, métodos y enfoques de operación, mediante los cuales un emprendimiento de inclusión socio-laboral genera valor en sus principales stakeholders. Asimismo, se busca que la metodología resultante, posibilite el reconocimiento de aquellas "buenas prácticas" de gestión, susceptibles de ser adoptadas por organizaciones de objetivo similar, a fin de maximizar el impacto en las comunidades donde operan.

Para el desarrollo de esta metodología se realizó un análisis documental de diferentes enfoques organizacionales utilizados en la planificación estratégica empresarial y en la evaluación del desempeño social. Por un lado, se utilizó el esquema de mapa estratégico propuesto por Kaplan y Norton (2004), y su respectiva adaptación a empresas sociales que trabajan por la inclusión socio-laboral elaborada por Murillo (2016, 2020). De otro lado, se analizó el aporte, que al diseño metodológico podría realizar la teoría de stakeholders y otros diferentes enfoques relacionados con la generación de valor compartido y la Responsabilidad Social Empresarial. 
De los citados análisis, se extrajeron los elementos y necesidades de información más relevantes a ser incluidas en un estudio de exploración sobre las posibles rutas, acciones y prácticas que desarrolla una organización social en su carrera por crear, mantener y maximizar valor dentro de sus grupos de interés. A partir de esta identificación, se procedió a diseñar un estudio de caso aplicable a emprendimientos sociales que trabajan en el campo de la inclusión socio-laboral.

El presente artículo se estructura de la siguiente manera: tras la introducción, se presenta el marco conceptual, donde se abordan diferentes teorías y enfoques de esencial interés para el desarrollo de la metodología objeto de este trabajo. En la sección tres, se describe el método y las etapas llevadas a cabo para la construcción metodológica, mientras que en la cuarta sección se detalla sobre el diseño final del estudio de caso y los avances preliminares en su aplicación. Finalmente, en la sección cinco, se recogen algunas conclusiones y reflexiones finales.

\section{Marco conceptual}

\subsection{El emprendimiento social y la creación de valor}

Se puede definir el emprendimiento social como aquel proyecto, empresa u organización que tiene por objetivo principal la atención de una necesidad o problemática social. Dees (1998), afirma que la característica esencial de este tipo de emprendimiento es el compromiso con su misión social que, en ninguna circunstancia, podrá reducirse a la generación de beneficios financieros privados. Si bien esta misión, puede o no, coexistir con el ánimo de lucro según la tipología del emprendimiento ${ }^{2}$, el objetivo económico nunca será entendido como un fin en sí mismo, sino como un medio para alcanzar un determinado bienestar social.

Actualmente, importantes entidades y organismos internacionales de desarrollo coinciden de algún modo con la conceptualización sobre emprendimiento social propuesta por Dees hace más de dos décadas. Por ejemplo, la Unión Europea, concibe este tipo de emprendimiento como un "operador" de la economía social, cuyo fin principal es la generación de impacto social (objetivo que se antepone a la obtención de beneficios financieros para los dueños o accionistas) y tiene como característica la transparencia e involucramiento de los stakeholders en su gestión (European Commission, 2021).

Al mismo tiempo, la Organización de Naciones Unidas sugiere que el emprendimiento social es aquel que busca crear valor o generar un impacto positivo en la sociedad, brindando productos, servicios o soluciones a retos sociales y necesidades básicas insatisfechas, generalmente, de colectivos marginalizados o en riesgo de exclusión (United Nations, 2020). Así entonces, la creación de impacto o valor social representa el mayor propósito de esta clase de organizaciones (Austin, Stevenson, \& Wei-Skillern, 2006; Dees, 1998; Mair \& Martí, 2006; Yunus, 2010).

A fin de comprender el impacto y la contribución que una organización puede realizar al desarrollo de una comunidad o territorio, se vuelve necesario precisar sobre lo que significa la "creación de valor social". Este término, cada vez más usado, aún no ha logrado un claro consenso y las definiciones propuestas por diferentes autores e instituciones, varían según su campo de estudio.

Austin, Gutierrez, Ogliastri y Reficco describen la creación de valor social como "la búsqueda del progreso social, mediante la remoción de barreras que dificultan la inclusión, la ayuda a aquellos temporalmente debilitados o que carecen de voz propia y la mitigación de efectos secundarios indeseables de la actividad económica" (2006: 296). Por otro lado, Social Value International ${ }^{3}$, propone que el valor social es la cuantificación de la importancia relativa que las personas otorgan a los cambios que experimentan en sus vidas, y que algunos de estos cambios (pero no todos) pueden ser representados en precios de mercado (Social Value UK, 2018, para. 1).

A partir de estos aportes, se puede inferir que la creación de valor social hace alusión a la generación de cambios positivos en la calidad de vida de las personas o de un determinado colectivo lo que, a su vez, estimula el desarrollo social ${ }^{4}$ dentro de una comunidad o región. El solo hecho de que el emprendimiento social se proponga resolver una problemática en un grupo específico, sugiere que dicha acción tendrá, inevitablemente, efectos sobre los individuos (bienestar individual) y su entorno (bienestar colectivo).

Ahora bien, aunque se tenga una idea más o menos clara del significado de valor social, su compresión, y especialmente, su "medición", resulta en una tarea sumamente compleja, pues exige la valoración de elementos y nociones subjetivas y abstractas relacionadas con el "bienestar humano" (Austin, Gutierrez, et

\footnotetext{
Conforme sea el modelo de ingresos adoptado (dependencia del mercado), y según otras variables como el grado de innovación y el nivel el compromiso con su misión, los emprendimientos sociales pueden ser clasificados en tres tipos: a) organizaciones sin ánimo de lucro; b) empresas sociales híbridas y c) empresas regulares innovadoras con ánimo de lucro (Lepoutre, Justo, Terjesen, \& Bosma, 2013).

Red global que trabaja en la creación y fortalecimiento de principios y metodologías para la medición y el análisis del impacto social.

En este escrito, tanto el término de "desarrollo social" como el de "valor social" hace referencia a las tres principales dimensiones del desarrollo sostenible (social, económica y medio ambiental).
} 
al., 2006) y el desarrollo en todas sus dimensiones. Ante la relatividad del concepto y los retos inherentes a su gestión y visibilización, las organizaciones y emprendimientos sociales acuden a diferentes metodologías, baterías de indicadores o guías de reportes de sostenibilidad que, de algún modo, puedan dar cuenta de su "desempeño social". Estas propuestas o instrumentos sientan sus bases en enfoques y teorías socioorganizacionales que ponen como centro de atención de la empresa, sus actuaciones e impactos en cada uno de sus grupos de interés (stakeholders). En los apartados subsiguientes se describen algunas de las teorías más relevantes en torno al "valor social" y que, particularmente, contribuyen a los objetivos del presente trabajo.

\subsection{Conceptos y enfoques alrededor del valor social: Responsabilidad Social Empresarial (RSE), Gestión de Stakeholders y Creación de Valor Compartido}

Han transcurrido décadas de evolución del concepto de Responsabilidad Social Empresarial desde la propuesta de Bowen en 1953, quien la planteó como una "obligación social del empresario" en cooperar con las acciones del estado para generar bienestar social (citado por Duque, Cardona y Rendón, 2013). Durante los años 80 se incrementó el interés sobre esta noción y se realizaron diversas contribuciones, dentro de las más relevantes, la de Edward Freeman. Este reconocido profesor de las ciencias empresariales, propuso la RSE como la búsqueda del cumplimiento de expectativas de los diferentes stakeholders, es decir, de aquellos grupos o individuos que puedan afectar o verse afectados por el logro de los objetivos de una organización, incluyendo a empleados, clientes, proveedores, accionistas, bancos, ambientalistas, gobierno, entre otros (Freeman \& Reed, 1983).

A partir de este aporte surge la teoría de stakeholders, la cual sugiere que la finalidad de toda empresa no se centra en la maximización del beneficio económico, sino en la creación de valor para todos sus grupos de interés (Albasu \& Nyameh, 2017; Retolaza, San-Jose, \& Ruiz, 2010). Bajo esta teoría se han desarrollado diferentes enfoques para identificar, analizar y evaluar la generación de valor social y sostenibilidad de cualquier tipo de organización. El Triple Botomm Line, por ejemplo, es un modelo formulado por John Elkington en la década de los 90, el cual sugiere tres grandes (y generales) grupos de interés con los cuales toda empresa interactúa: a) los accionistas, b) la sociedad y c) el medio ambiente (Elkington, 2013). Estas dimensiones, conocidas como las 3P's (people, planet, profits), conforman un marco para la evaluación del desempeño y la rendición de cuentas de la organización considerando tres factores esenciales: el financiero, el social y el medioambiental (Slaper \& Hall, 2011).

Es así, que las organizaciones "orientadas al valor social" deben asimilar la teoría de stakeholders como un enfoque de gestión, donde el dialogo permanente con los grupos de interés es una acción fundamental. De acuerdo a González (2017), esta teoría representa un nuevo paradigma empresarial, centrado en un modelo de organización plural, en el cual, se reconoce la diversidad de actores que intervienen o se ven afectados por esta. Asimismo, exige el reconocimiento y evaluación de las necesidades y expectativas de los grupos y del grado de legitimidad de estas.

La idea de la "satisfacción de necesidades o cumplimiento de expectativas" de los stakeholders se constituye en la base de cualquier estrategia de RSE y de los modelos de evaluación de desempeño social. Esta noción, se hace evidente en los enfoques vigentes más aceptados, tal es el caso de la norma internacional ISO 26000 "Guía de Responsabilidad Social", que plantea la RSE como la:

Responsabilidad de una organización ante los impactos que sus decisiones y actividad ocasionan en la sociedad y el medio ambiente, mediante un comportamiento ético y transparente que: a) contribuya al desarrollo sostenible; b) tome en consideración las expectativas de sus partes interesadas; c) cumpla con la legislación aplicable y sea coherente con la normatividad internacional de comportamiento y; d) esté integrada en toda la organización. (Organización Internacional de Normalización, 2010: 3).

La RSE no solo ha evolucionado en cuanto a su definición conceptual, sino también, en sus orientaciones de aplicación. En las décadas de los 70 y 80, la Responsabilidad Social se concebía más como un conjunto de actividades de corte altruista, sin permear o involucrar la gestión organizacional. Hoy en día, esta es vista de manera más integral y transversal a los procesos de la organización, hace parte de la planificación estratégica e, incluso, se constituye en un modelo de operación, que además de beneficiar a la empresa, contribuye con el desarrollo sostenible de las comunidades.

La profesora Adela Cortina, confirma que la Responsabilidad Social no se trata de filantropía ni de llevar a cabo acciones de beneficencia desinteresadas, sino más bien de "diseñar las actuaciones de la empresa, de forma que tengan en cuenta los intereses de todos los afectados por ella y sea medible el deseable progreso" (2009: 121). Igualmente, fortalece la idea de la RSE como herramienta de gestión dentro de una dimensión ética de la empresa, que va mucho más allá, de un puro marketing social.

Otros dos importantes conceptos, frecuentemente relacionados a la RSE, a la teoría de stakeholders y a la gestión del impacto social son el de shared value (valor compartido) y el de blended value (valor combinado 
o mixto). Porter y Kramer, han definido la creación de valor compartido (CVC) como "las políticas y las prácticas operacionales que mejoran la competitividad de una empresa a la vez que ayudan a mejorar las condiciones económicas y sociales en las comunidades donde opera" (2011: 6). La CVC permite que las empresas adopten una visión de la RSE de manera más estratégica que reactiva, es decir, que en lugar de limitarse a reducir o eliminar impactos negativos en los stakeholders, desarrollen iniciativas con alto potencial de crear valor (económico y social) en los diversos grupos de interés (Muñoz-Martin, 2013). Esto significa, que las organizaciones deben detectar las actividades de la cadena de valor susceptibles de generar mayor impacto, y buscar mejorarlas para maximizar tanto el valor social como las ventajas competitivas y, en consecuencia, el valor económico para los dueños o accionistas.

De otro lado, el blended value hace referencia a las capacidades de las empresas, para generar valor de tipo económico, social y medioambiental por medio de sus inversiones y proyectos (Buckland \& Murillo, 2014; Emerson, 2003; Narrillos, 2012). A. Nicholls (2009) plantea que todas las organizaciones crean valor económico y social, y que estos dos tipos de valor no son excluyentes, antes bien, se encuentran intrínsicamente conectados. A pesar de que no se evidencia suficiente literatura que aporte claridad sobre cómo las estrategias de inversión de valor combinado influyen concretamente en los rendimientos financieros de una empresa, si se ha demostrado que cierto tipo de proyectos e inversiones pueden aportar, tanto beneficios financieros, como sociales y medio ambientales (Harold, Spitzer, \& Emerson, 2007).

Para Bugg-Levine y Emerson (2011), el concepto de blended value reta a las organizaciones a comprender el "valor" de una manera diferente; no entenderlo como la suma de componentes independientes de un triple resultado (económico, social y medioambiental), sino como una "combinación indivisible" de estos tres elementos y de los esfuerzos conjuntos provenientes del capital, la comunidad y el comercio. En palabras de Ibarra-Baidón, el valor combinado reside en aquellas estrategias innovadoras que buscan generar impacto económico, social y ambiental de una manera sinérgica, en lugar de poner a competir estos tres tipos de valor, para así, maximizar los beneficios de todas las partes interesadas (2019).

El desarrollo de un enfoque para el análisis y evaluación del valor social debería contemplar estos planteamientos, pues es claro que tanto el shared value, como el blended value, trascienden la concepción del "valor" y no lo limitan a un simple hecho economicista que beneficia únicamente a los dueños o accionistas de una organización, sino que, por el contrario, incluye paralelamente, la generación de bienestar para los otros grupos de interés y en general, para la sociedad.

\subsection{Modelos y estándares para la gestión, medición y reporte del desempeño social organizacional}

Conforme han aparecido y progresado los conceptos de valor social, desarrollo sostenible, ética empresarial y RSE, diferentes instituciones y organismos se han dado a la tarea de diseñar y proponer mecanismos, modelos y métricas para la gestión y comunicación del "desempeño social" de una organización. En la actualidad existe una proliferación de normas y guías que, según Duque et al.(2013), tienen una estructura similar y unos elementos unificadores, entre otros: a) el cumplimiento de los estándares y requisitos mínimos en cuanto a derechos humanos y laborales; b) la reducción o eliminación de los impactos negativos en el medio ambiente; c) el fomento de la transparencia, el buen gobierno y la adecuada comunicación y d) la búsqueda del cumplimiento de las expectativas legítimas de los stakeholders más relevantes de la organización.

A pesar de que estos estándares se han planteado con un buen propósito, existe un debate sobre la utilidad y verdadero impacto derivado de su uso. Strandberg afirma que: "Muchas empresas que han publicado informes de sostenibilidad o RSE han sido acusadas de hacerlo solo a modo de escaparate, de no actuar siguiendo sus propias recomendaciones o de no informar sobre los asuntos que son realmente cruciales." (2010:7). Aun así, no se puede menospreciar el importante aporte que estas guías y los organismos que las construyen han realizado en pro de fomentar el compromiso de las empresas con sus stakeholders y con el medio ambiente. En la tabla 1 se presenta, de manera resumida, algunos de los modelos más reconocidos y que son objeto de análisis para la construcción metodológica que nos ocupa. 
Tabla. 1. Principales referentes para la gestión, medición y comunicación del impacto social y las estrategias de RSE

\begin{tabular}{lll}
\hline Estándar/referente Objetivo / Descripción & Principios / Criterios de evaluación
\end{tabular}

Los 10 Principios Propone un marco práctico para las empresas Contiene 10 principios distribuidos en del Pacto Mundial / comprometidas con la sostenibilidad y las cuatro esferas: 1) derechos humanos; 2) Naciones Unidas prácticas empresariales responsables. Se basa en la estándares laborales; 3) medio ambiente y rendición pública de cuentas (informe de 4) lucha contra la corrupción. progreso). Es un estándar de adopción voluntaria.

ISO 26000: Guía Proporciona orientación a todo tipo de Propone 36 asuntos distribuidos en siete de Responsabilidad organizaciones sobre los conceptos, principios y materias fundamentales $\left.{ }^{5}: 1\right)$ gobernanza,

Social $/$

Organización

Internacional de

Normalización

prácticas relacionadas con la RSE. Busca ayudar a las organizaciones a maximizar su contribución al desarrollo sostenible. Se compone de siete capítulos y dos anexos. Es una guía voluntaria NO certificable. SA 8000 / Social
Accountability International

Estándar basado en la Declaración de Derechos Humanos y en las normas internacionales de trabajo y derechos laborales. Tiene como objetivo empoderar y proteger todo el personal de una organización y promover prácticas socialmente aceptables en los puestos y lugares de trabajo. Norma auditable y certificable en lugar de trabajo específico.

2) derechos humanos; 3) prácticas laborales; 4) medio ambiente; 5) prácticas justas de operación; 6) consumidores y

7) participación activa y desarrollo de la comunidad.

\begin{tabular}{lll}
\hline Estándares GRI / & Describe las mejores prácticas para informar sobre GRI 100 (estándares universales aplicables \\
Global Reporting & los impactos económicos, ambientales y sociales cualquier tipo de organización); GRI 200
\end{tabular} Initiative de una organización. Es una compilación de (impactos económicos); GRI 300 (impactos estándares para la elaboración de informes de ambientales) y GRI 400 (impactos sociales). sostenibilidad. Se compone de una serie de Sobre los últimos tres estándares temáticos, estándares universales y tres series de estándares las organizaciones pueden seleccionar cuales temáticos. Es una guía voluntaria. usar en función de su sector y áreas de mayor impacto.

\begin{tabular}{lll}
\hline Balance del Bien & Herramienta de gestión del desempeño ético y Propone 20 criterios de desempeño social que \\
Común & social empresarial basada en la Matriz del Bien resultan de la relación entre las necesidades \\
& Común. Más que un que un sistema de medición, de los grupos de interés clave de toda \\
& propone la aplicación de una escala de valores del empresa (proveedores; propietarios y \\
& Bien Común a las actividades concretas de una proveedores financieros; empleados/as; \\
& organización y el análisis de su impacto en los clientes y entorno social) y cuatro valores \\
& stakeholders. Es una guía voluntaria, universales (dignidad humana; solidaridad y \\
& potencialmente auditable y certificable a petición justicia; sostenibilidad medioambiental; \\
& de la organización. & transparencia y participación democrática). \\
\hline
\end{tabular}

Fuente: Elaboración propia con datos de GRI (2018), Naciones Unidas (2009), Organización Internacional de Normalización - ISO (2010), Social Accountability International (2014) y Blachfellner et al. (2017)

Varios de los referentes anteriormente citados, han sido de consideración y relevancia en el contexto europeo. La Comisión Europea, quien concibe la RSE como "la integración voluntaria, por parte de las empresas, de las preocupaciones sociales y medioambientales en sus operaciones comerciales y sus relaciones con sus interlocutores" (2011:4), dentro de su Estrategia renovada de la UE para 2011-2014 sobre la responsabilidad social de las empresas, invita a las empresas europeas a adoptar los principios y lineamientos de estándares como el Pacto Mundial de las Naciones Unidas o la guía ISO 26000.

Adicionalmente, desde el año 2014, la Unión Europea estableció en la Directiva 2014/95 un conjunto de criterios y requisitos que las empresas europeas deben cumplir, en referencia al reporte de información no financiera dentro de sus informes de gestión. Dicho lineamiento incluye la obligación de reportar los resultados e impactos de su actividad relacionados con el medio ambiente, los derechos humanos y la lucha contra la corrupción, entre otros aspectos sociales (Parlamento Europeo, 2014).

\subsection{Valor social y desarrollo sostenible: la integración de los Objetivos de Desarrollo Sostenible (ODS) a la cadena de valor de la organización}

Al igual que la RSE, el concepto de desarrollo sostenible (DS) viene fortaleciéndose en los últimos años como respuesta a las necesidades de introducir cambios al modelo de desarrollo económico predominante, y de definir límites al crecimiento desmesurado. El DS, entendido al día de hoy como aquel desarrollo que "satisface las necesidades de las generaciones presentes sin comprometer la capacidad de las generaciones

\footnotetext{
El capítulo 6 de la guía explica las materias fundamentales relacionadas con la RSE y sus asuntos asociados. Estas materias cubren los impactos más probables, tanto de tipo económico, como ambiental y social, que deberían abordar las organizaciones.
} 
futuras para satisfacer sus propias necesidades" (Naciones Unidas, 2018a, párr. 1) consta de tres dimensiones básicas: a) la social, b) la medio ambiental y c) la económica.

La dimensión social busca garantizar condiciones para el bienestar de las personas y la sociedad, lo cual conlleva al desarrollo de acciones que no atenten contra los derechos humanos, económicos, políticos y culturales de los colectivos y grupos sociales. La sostenibilidad ambiental se refiere a la capacidad de mantener relaciones de equilibrio con la naturaleza, es decir, que las actividades humanas no supongan la degradación del medio ambiente ni el agotamiento de los recursos naturales. Finalmente, la dimensión económica hace alusión a la generación de ingresos y empleo, que sirvan como medio de sustento de una población para mantener una vida digna.

Como se observa, la descripción de las dimensiones del DS, evidencian una estrecha relación con los demás conceptos y teorías desarrolladas en los dos apartados anteriores. La RSE, la teoría de stakeholders y los conceptos de shared value y blended value contemplan la creación y maximización de valor en las mismas tres esferas: social, económica y medio ambiental. Por tanto, puede inferirse que las acciones desarrolladas por un emprendimiento social en cualquiera de estas dimensiones tendrán un potencial impacto en el desarrollo sostenible del territorio y comunidades donde opera.

Los actuales Objetivos de Desarrollo Sostenible (ODS) constituyen el principal marco o referente de actuación para lograr el DS, pues marcan una ruta clara para el progreso y el desarrollo mundial en los años venideros (Agenda 2030 para el Desarrollo Sostenible) $)^{6}$. Es necesario apuntar que, tal y como lo afirma el PNUD, la consecución de estos objetivos, requiere de un alto grado de colaboración por parte de los gobiernos, el sector privado, la sociedad civil y los ciudadanos (Naciones Unidas, 2018b).

Para responder a esta demanda, las empresas públicas, privadas y sociales, deberán comprometerse con la definición e implementación de estrategias encaminadas a incrementar los impactos sociales positivos en el planeta y las personas y, a su vez, a eliminar o reducir al máximo los impactos negativos. Algunas instituciones y organismos de desarrollo se han dado a la tarea de crear y proponer metodologías e instrumentos de gestión que ayuden a estas empresas a alinear sus objetivos y estrategias con los ODS y así, cumplir con su compromiso social y ambiental.

Dentro de las diferentes propuestas se destaca el SDG Compass, herramienta elaborada en el año 2016 por el GlobaI Reporting Initiative (GRI), el Pacto Mundial de las Naciones Unidas y el Consejo Empresarial Mundial para el Desarrollo Sostenible (WBCSD). Este instrumento, sirve de ruta para las empresas, que independientemente de su tamaño o sector, deseen evaluar la contribución de sus actividades a los ODS, y se compone de cinco pasos: 1) Entender los ODS e identificar cuáles de ellos representan responsabilidades u oportunidades para la organización; 2) Definir prioridades de la organización y evaluar impactos de las acciones de la cadena de valor sobre los ODS; 3) Establecer objetivos de sostenibilidad concretos; 4) Integrar los objetivos de sostenibilidad a las actividades de la empresa y 5) Reportar y comunicar a las partes interesadas sobre los avances (GRI, Pacto Global de las Naciones Unidas, \& WBCSD, 2016).

Por otra parte, la Agencia Española de Cooperación Internacional para el Desarrollo (AECID), en su "Estudio sobre la contribución de la empresa a la agenda de los objetivos de desarrollo sostenible" reafirma que todas las empresas pueden aportar al logro de los ODS, bien sea desde su actividad principal o por medio de una gestión responsable con sus diferentes stakeholders. Es así, que tras un proceso de investigación y análisis riguroso, en el cual contempló, no solo los pasos propuestos por el SDG Compass, sino otros trabajos previos realizados por Naciones Unidades y reconocidas firmas consultoras/auditoras (Accenture y PricewaterhouseCoopers), propuso una guía para orientar a cualquier tipo de organización en el proceso de alineación de su estrategia con los Objetivos de Desarrollo Sostenible (AECID, 2017). La guía se compone de 17 fichas (correspondientes a los 17 ODS), y en cada una de estas, se describe las herramientas y posibles acciones estratégicas que cada organización, de acuerdo a su sector ${ }^{7}$, podría implementar para maximizar su aporte a las metas de DS.

El emprendimiento social no es ajeno al compromiso que plantea la Agenda $2030 \mathrm{y}$, antes bien, recae en el un mayor nivel de responsabilidad, debido a su especial misión centrada en la creación de valor social. Articular las acciones y objetivos de los emprendimientos con los ODS resulta clave, no solo para el cumplimiento de un gran "pacto global", sino como estrategia organizacional para la maximización del valor en los grupos atendidos. El primer ejercicio para lograr dicha alineación y comprender más ampliamente el probable impacto que los emprendimientos sociales objeto de este estudio pueden realizar al desarrollo sostenible local y regional, es identificar cuáles de los 17 ODS representan compromisos, desafíos u oportunidades. Dicho impacto podrá darse de una manera directa, desde la ejecución de la misión y acciones

6 En septiembre de 2015, los 193 Estados miembros de las Naciones Unidas, proclamaron la Agenda 2030 para el Desarrollo Sostenible, la cual integra las tres dimensiones del DS (económica, social y ambiental) y define 17 objetivos, con 169 metas, que se esperan cumplir en los 15 años sucesivos (Naciones Unidas, 2018b).

La guía de AECID propone acciones puntuales para más de 20 sectores estratégicos, entre los más relevantes: a) Actividades sanitarias y de servicios sociales; b) Educación; c) Suministro de energía; de) Suministro de agua; e) Actividades financieras y de seguros; f) Administración pública y defensa; g) Actividades de los hogares como empleadores; h) Agricultura y ganadería; i) Transporte y almacenamiento; j) Industria manufacturera; k) Construcción; 1) Información y comunicaciones; m) Comercio y n) Hostelería. 
propias del emprendimiento o, de una manera indirecta, por medio de la adopción de "buenas prácticas" para asumir las responsabilidades mínimas que cualquier empresa tiene frente a temas tan esenciales como los derechos humanos y el cuidado ambiental.

En la tabla 2 se describen los ODS y metas de desarrollo asociadas al quehacer de los emprendimientos sociales que trabajan por la inclusión socio-laboral. Adicionalmente, se incluyen algunas prácticas o acciones recomendadas por la citada guía de AECID en diferentes sectores estratégicos, que resultan potencialmente aplicables a este tipo de emprendimientos dado sus característicicas y misionalidad, entre otras, las relacionadas con: a) el apoyo financiero y ofrecimiento de servicios microfinancieros a grupos en riesgo de exclusión; b) los programas educativos y de formación para el empleo; c) el fomento del voluntariado y d) las políticas y buenas prácticas laborales al interior de la organización.

Tabla. 2. Priorización de los ODS en emprendimientos sociales que trabajan por la inclusión socio-laboral de colectivos vulnerables

ODS / Meta abreviada

- Otorgar microcréditos como herramienta de lucha contra la pobreza.

ODS 1. Fin de la pobreza

Meta 1.4: Igualdad de derechos a recursos $\bullet$ Fomentar negocios inclusivos que incluyan a personas de la económicos, servicios y propiedad. base de la pirámide.

- Apoyar a emprendedores y PYMES para que generen tejido industrial sostenible.

\section{ODS 4. Educación de calidad}

- Ofrecer oportunidades de formación continua a empleados para mejorar sus competencias.

Meta 4.4: Aumentar jóvenes y adultos con • Fomentar actividades de voluntariado propiciando un doble competencias técnicas y profesionales para el acceso al empleo y el emprendimiento.

Meta 4.5: Acceso igualitario a la educación (no discriminación). resultado: la mejora de las capacidades de los propios voluntarios y facilitando la empleabilidad de distintos colectivos en riesgo de exclusión.

- Desarrollar programas de prácticas para estudiantes.

\section{ODS 5. Igualdad de género}

Meta 5.1: Poner fin a todas las formas de discriminación contra mujeres y niñas.

Meta 5.5: Igualdad de oportunidades y participación de las mujeres en posiciones de liderazgo.

ODS 8. Trabajo decente y crecimiento económico

Meta 8.3: Promover políticas para apoyar la creación del empleo, la innovación y el crecimiento de las micro, pequeña y mediana empresa.

- Implantación de planes de igualdad con impacto en la contratación, la retribución, la promoción, etc.

- Instaurar políticas de tolerancia cero hacia cualquier forma de violencia laboral (abusos verbales y físicos).

- Apoyo financiero a jóvenes emprendedores.

- Promoción de las microfinanzas destinadas a colectivos en riesgo de exclusión.

- Evaluar la cadena de suministro en materia de DDHH.

Meta 8.5: Lograr el empleo pleno y productivo y el • Implantación de los Principios Rectores sobre Empresas y trabajo decente, así como la igualdad de remuneración.

Meta 8.6: Reducir desempleo juvenil.

Meta 8.8: Proteger los derechos laborales y promover un entorno de trabajo seguro.

Derechos Humanos de Naciones Unidas.

- Promocionar programas de formación para establecer buenas prácticas de salud y seguridad en el trabajo a lo largo de la cadena de valor.

ODS 10. Reducción de las desigualdades

- Impulsar campañas de sensibilización para promover una sociedad justa e igualitaria.

Meta 10.2 Promover la inclusión social, económica y política de todas las personas.

- Desarrollar políticas de igualdad y de no discriminación.

- Cooperar con ONG's que trabajan por la inclusión.

Las teorías, modelos y propuestas descritas en este capítulo brindan una común y centrada idea sobre los objetivos, estrategias y medios que el emprendimiento social (o cualquier otra organización que pretenda ser socialmente responsable) puede utilizar en pro de maximizar el impacto social, económico y medio ambiental en sus principales stakeholders. Estos enfoques y conceptos son el principal insumo para la construcción de la metodología que propone el presente trabajo, tal y como se detalla en los apartados subsiguientes. 


\section{Construcción de la metodología}

Entender las formas y vías por medio de las cuales un emprendimiento social genera impacto en sus grupos de interés exige, primero que todo, identificar y comprender aquellas relaciones y vínculos causales entre las acciones desarrolladas por la organización y los cambios que se pueden evidenciar en los diferentes stakeholders. De acuerdo a Flores (2016), esta comprensión, permitirá que la organización incluya en su estrategia (en sus prácticas, servicios y acciones) lo que realmente es relevante para generar los resultados sociales esperados.

Es por este motivo, que la metodología propuesta sienta sus bases en un instrumento de planeación y gestión organizacional denominado el Mapa Estratégico. Esta herramienta, al igual que los modelos lógicos ${ }^{8}$, explica la generación de valor a través de relaciones de causalidad. El Mapa Estratégico es una representación gráfica que describe vínculos causales entre los diferentes componentes de una estrategia organizacional (misión, objetivos, acciones) por medio de cuatro perspectivas básicas: financiera; del cliente; de los procesos internos y de aprendizaje y crecimiento (Kaplan \& Norton, 2004).

Para los propósitos específicos de este trabajo, se retomó la propuesta de Murillo (2016, 2020), la cual plantea un mapa estratégico adaptado para entidades y proyectos de empleo inclusivo, que considera la variación de los términos, conceptos y jerarquías de un mapa estratégico convencional, según las particularidades de los emprendimientos sociales de inclusión socio-laboral (ver figura 1).

Figura. 1. Adaptación del modelo de mapa estratégico para emprendimientos sociales que trabajan por la inclusión socio-laboral de colectivos vulnerables
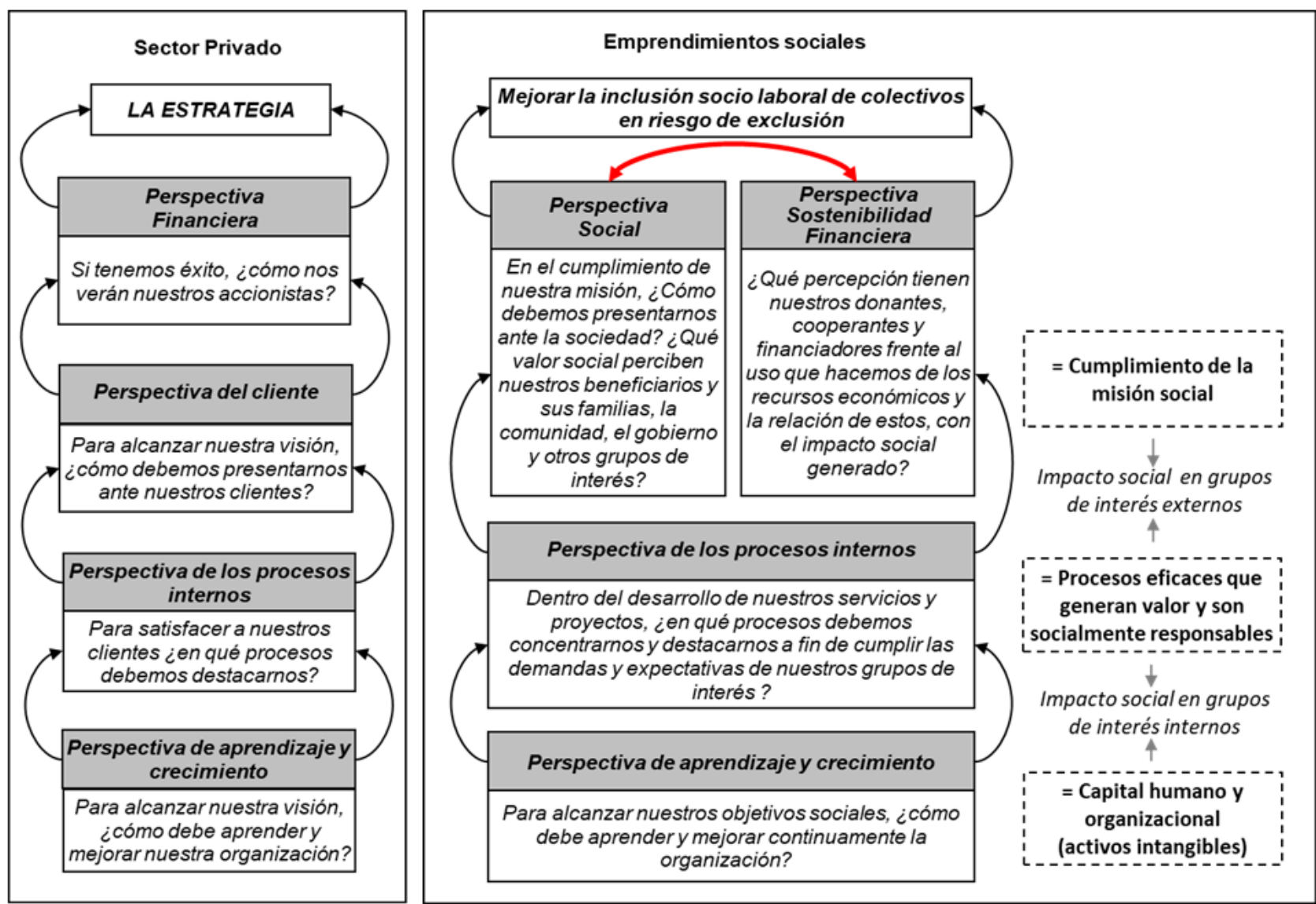

Fuente: Elaboración propia con datos de Kaplan y Norton (2004) y Murillo (2016, 2020)

Como bien puede observarse, de este modelo de generación valor, emergen varios cuestionamientos que incitan a la organización a reflexionar sobre los impactos generados en sus diferentes stakeholders. Este mapa estratégico sugiere que, por medio de la planificación y ejecución eficiente de los procesos de la cadena de valor, la organización se acercará al cumplimiento de sus objetivos sociales y de sostenibilidad financiera y, por tanto, creará impacto en sus grupos de interés externos (beneficiarios, gobierno y

8 Teorías o modelos que explican la forma en que una intervención/proyecto produce los impactos deseados (Teoría de Cambio, Cadena de Resultados, Enfoque de Marco Lógico). 
financiadores, entre otros). De otro lado, si la organización, además de garantizar procesos internos eficaces y socialmente responsables, lleva a cabo estrategias efectivas para el fortalecimiento de sus activos intangibles (capital humano y organizacional), consecuentemente, estará generando valor para otros grupos de interés internos como los empleados y voluntarios.

A partir de este enfoque, se desarrollaron entonces las siguientes etapas para la construcción metodológica de un estudio de caso: a) identificación de stakeholders; b) definición de criterios de gestión social; c) bosquejo de mapa estratégico para emprendimientos de inclusión socio-laboral y d) diseño del estudio de caso.

\subsection{Identificación, delimitación y selección de los principales stakeholders}

Entendiendo que el objeto de este trabajo se centra en la generación de valor social en los diferentes stakeholders de los emprendimientos sociales de inclusión socio-laboral, se hace necesario delimitar aquellos grupos de interés (internos y externos), sobre los cuales, dichos emprendimientos tienen mayor potencial de impacto. Para dicha selección, además de considerar los resultados del trabajo previo de Murillo (2020), también se realizó una revisión documental de otros estudios relacionados a los stakeholders en las organizaciones sociales.

La definición de estos stakeholders no podría limitarse únicamente a aquellos grupos que se benefician directamente de los servicios o proyectos ejecutados por la organización. Ineludiblemente, deben incluirse al análisis otro tipo de elementos como las posiciones de poder, legitimidad y urgencia (Mitchell, Agle, \& Wood, 1997) y el tipo de demandas/expectativas específicas de cada grupo, entre otras, las referentes a: resultados sociales y financieros; condiciones de bienestar; sostenibilidad ambiental; desarrollo profesional; relaciones justas y de beneficio mutuo e información. Para esta útima demanda, por ejemplo, Maguregui Urionabarrenechea, Corral Lage y Elechiguerra Arrizabalaga (2018), concluyen que los principales stakeholders de toda $\mathrm{ESFL}^{9}$ en relación a la información transparente son: a) los socios, patronos o donantes; b) los usuarios; c) los voluntarios y d) los empleados.

En tanto, una vez realizados los respectivos análisis, se definieron y agruparon los principales stakeholders de los emprendimientos objeto de estudio, en las siguientes categorías: a) Beneficiarios, usuarios o participantes y sus familias; b) Gobierno, entidades público-privadas y otros agentes sociales; c) Financiadores, donantes y cooperantes; d) Empleados, voluntarios y colaboradores; e) Gerentes, líderes y gestores del emprendimiento social y f) Proveedores.

\subsection{Definición de criterios de gestión social}

Posterior a la definición de los stakeholders, se consideró necesario ahondar en la identificación y análisis de elementos puntuales de generación de valor social (estrategias) en función de las demandas y expectativas de estos grupos y de las perspectivas del mapa estratégico. Por un lado, se revisó y analizó la documentación de la planificación estratégica y los modelos de operación de dos organizaciones valencianas que trabajan en el campo del empleo inclusivo: la Asociación Alanna ${ }^{10}$ y el Servicio Valenciano de Empleo y Formación ${ }^{11}$. La selección de dichas organizaciones se realizó con base a los siguientes criterios: a) que la inclusión sociolaboral fuera el principal objetivo estratégico de la entidad; b) que independientemente de su tamaño, tuviera un modelo de operación y plan estratégico "documentado" y c) que dicha información estratégica fuera pública o suministrada por la misma organización.

De otro lado, se examinaron los criterios y requisitos relacionados al desempeño social organizacional que proponen diversos enfoques y modelos de RSE y/o desarrollo sostenible, y que son suceptibles de aplicar a los emprendimientos sociales de inclusión socio-laboral. En total, se incluyeron en el análisis 206 criterios; el 60\% provenientes de los estándares de RSE (descritos en el apartado 2), el $30 \%$ extraidos de la planificación estratégica de las organizaciones seleccionadas y el 10\% correspondiente a los principios de desarrollo sostenible materializados en las metas ODS. El estudio de estos elementos implicó, además, la visibilización de las necesidades y expectivas de los principales grupos de interés. Los stakeholders mayoritariamente representados en los criterios analizados fueron: los beneficiarios y sus familias (40\% de los criterios involucraron este grupo); los empleados (28\%) y la comunidad y el medio ambiente (21\%).

Entidades Sin Fines de Lucro

10 Alanna es una asociación valenciana que trabaja por la inclusión social real de las mujeres promoviendo la igualdad de género efectiva. Su misión es "contribuir al logro y desarrollo de una sociedad inclusiva, sostenible e igualitaria, desarrollando programas locales que provoquen la inclusión social de los colectivos más vulnerables, principalmente las mujeres, menores y familias (...)” (Asociación Alanna, 2014: 18). http://www.alanna.org.es/entidad/.

11 El Servicio Valenciano de Empleo y Formación - SERVEF (y ahora llamado LABORA), es un organismo autónomo de la Generalitat Valenciana que ofrece servicios públicos gratuitos para mejorar la empleabilidad de los ciudadanos. Su misión es "Trabajar por y para el empleo, ofreciendo a los ciudadanos de la Comunitat Valenciana la posibilidad de mejorar su capacitación profesional y su promoción individual, en aras a su incorporación, reingreso o mantenimiento en el mercado laboral". (SERVEF, 2014: 38). http://www.labora.gva.es/. 
La matriz "Análisis de Criterios de Gestión Social”, ejemplificada en la figura 2, permitió entonces listar, explorar y comparar todos estos criterios que, posteriormente, podrían dar lugar a la generación de estrategias organizacionales orientadas a la maximización de valor social y, por tanto, se convierten en foco de estudio para nuestra metodología de investigación. Adicionalmente, estos criterios, fueron catalogados y codificados según la función que puedan desempeñar en el modelo de operación y gestión del emprendimiento social. Es así, que cada criterio analizado puede verse representado en: a) un objetivo estratégico, b) una condición de gestión o c) una buena práctica para la generación de valor.

Los "objetivos estratégicos" se refieren a aquellos fines específicos, de mediano-largo plazo, trazados por la organización social, a fin de cumplir su misión y de generar valor para ella misma o para un grupo de interés determinado. Las "condiciones de gestión" representan aquellos requisitos mínimos e ineludibles asociados a uno o más objetivos, pues el no cumplimiento de alguno de estos podría, incluso, dar lugar a impactos "negativos" en los grupos de interés asociados. Finalmente, las "buenas prácticas" son aquellas estrategias o acciones de carácter "opcional", pero de alta pertinencia, que el emprendimiento podría decidir adoptar como medio para lograr el objetivo estratégico al que se vincula y, así, maximizar el valor social en el respectivo stakeholder. En otras palabras, las prácticas son aquellos elementos que promueven el logro del objetivo estratégico y, por tanto, estimulan la creación de valor. 
Figura. 2. Extracto de la matriz "Análisis de Criterios de Gestión Social”.

\begin{tabular}{|c|c|c|c|c|c|c|c|c|c|c|c|c|c|c|c|}
\hline \multirow[b]{2}{*}{ Objetivo / criterio / principio } & \multirow[b]{2}{*}{$\begin{array}{l}\text { Enfoque / } \\
\text { Modelo }\end{array}$} & \multirow[b]{2}{*}{$\begin{array}{l}\text { Organización } \\
\text { /autor }\end{array}$} & \multicolumn{10}{|c|}{ Stakeholder } & \multirow[b]{2}{*}{$\begin{array}{c}\text { Perspectiva } \\
\text { Mapa } \\
\text { Estratégico }\end{array}$} & \multirow[b]{2}{*}{$\begin{array}{l}\text { Objetivo/ } \\
\text { Condición/ } \\
\text { Práctica }\end{array}$} & \multirow[b]{2}{*}{$\begin{array}{c}\text { Cod. } \\
\text { Mapa } \\
\text { estratégico }\end{array}$} \\
\hline & & & 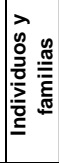 & 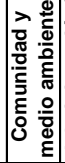 & 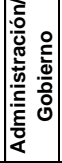 & 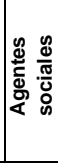 & 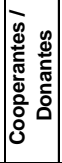 & 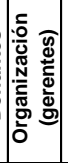 & 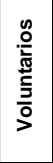 & 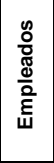 & 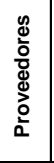 & 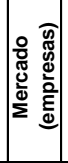 & & & \\
\hline $\begin{array}{l}\text { Incrementar competencias técnicas y } \\
\text { profesionales para el acceso al empleo, el } \\
\text { trabajo decente y el emprendimiento, } \\
\text { especialmente en personas vulnerables }\end{array}$ & $\begin{array}{l}\text { Desarrollo } \\
\text { Sostenible - ODS }\end{array}$ & $\begin{array}{l}\text { Naciones } \\
\text { Unidas (2015) }\end{array}$ & $\mathrm{x}$ & & & & & & & & & $\mathrm{x}$ & Social & Objetivo & S7 \\
\hline $\begin{array}{l}\text { Fomentar el emprendimiento, la } \\
\text { formalización y el crecimiento de las } \\
\text { microempresas }\end{array}$ & $\begin{array}{l}\text { Desarrollo } \\
\text { Sostenible - ODS }\end{array}$ & $\begin{array}{l}\text { Naciones } \\
\text { Unidas (2015) }\end{array}$ & $\mathrm{x}$ & & $\mathrm{x}$ & & & & & & & $x$ & Social & Objetivo & S6 \\
\hline $\begin{array}{l}\text { Lograr empleo pleno y productivo para } \\
\text { mujeres, hombres y personas con } \\
\text { discapacidad }\end{array}$ & $\begin{array}{l}\text { Desarrollo } \\
\text { Sostenible - ODS }\end{array}$ & $\begin{array}{l}\text { Naciones } \\
\text { Unidas (2015) }\end{array}$ & $\mathrm{x}$ & & $\mathrm{x}$ & & & & & & & & Social & Objetivo & S4 \\
\hline $\begin{array}{l}\text { Proteger los derechos laborales y garantizar } \\
\text { un entorno de trabajo seguro }\end{array}$ & \begin{tabular}{|l|} 
Desarrollo \\
Sostenible - ODS
\end{tabular} & $\begin{array}{l}\text { Naciones } \\
\text { Unidas (2015) }\end{array}$ & & & & & & & & $\mathrm{x}$ & & & $\begin{array}{l}\text { Aprendizaje y } \\
\text { crecimiento }\end{array}$ & Condición & $\mathrm{C} 20$ \\
\hline $\begin{array}{l}\text { Trabajar en contra de la corrupción en todas } \\
\text { sus formas (incluidas la extorsión y soborno) }\end{array}$ & Estándares RSE & $\begin{array}{l}\text { Pacto Mundial } \\
(2000)\end{array}$ & & & & & & $\mathrm{x}$ & & & $x$ & $\mathrm{x}$ & \begin{tabular}{|l|}
$\begin{array}{l}\text { Procesos } \\
\text { Internos }\end{array}$ \\
\end{tabular} & Condición & C14 \\
\hline $\begin{array}{l}\text { Desarrollo humano y formación en el lugar } \\
\text { de trabajo (empleados) - Asunto 5. Prácticas } \\
\text { Laborales }\end{array}$ & Estándares RSE & ISO $26000: 2010$ & & & & & & & $x$ & $\mathrm{x}$ & & & $\begin{array}{l}\text { Aprendizaje y } \\
\text { crecimiento }\end{array}$ & Objetivo & A1 \\
\hline $\begin{array}{l}\text { Prevención de la contaminación - Asunto } 1 \\
\text { Medio Ambiente }\end{array}$ & Estándares RSE & ISO $26000: 2010$ & & $\mathrm{x}$ & & & & & & & & & \begin{tabular}{|l|}
$\begin{array}{l}\text { Procesos } \\
\text { Internos }\end{array}$ \\
\end{tabular} & Condición & $\mathrm{C} 13$ \\
\hline $\begin{array}{l}\text { Participación política responsable (sin } \\
\text { clientelismo ni indebidas influencias) - } \\
\text { Asunto } 2 \text { Prácticas justas de operación }\end{array}$ & Estándares RSE & ISO $26000: 2010$ & & & $x$ & $\mathrm{x}$ & $\mathrm{x}$ & $\mathrm{x}$ & & & & & \begin{tabular}{|l} 
Sostenibilidad \\
Financiera
\end{tabular} & Condición & $\mathrm{C} 4$ \\
\hline $\begin{array}{l}\text { Participación activa de la comunidad - } \\
\text { Asunto } 1 \text { Particpación activa y desarrollo de } \\
\text { la comunidad }\end{array}$ & Estándares RSE & ISO $26000: 2010$ & $x$ & $x$ & $x$ & $x$ & & & & & & $x$ & $\begin{array}{l}\text { Procesos } \\
\text { Internos }\end{array}$ & Condición & $\mathrm{C} 7$ \\
\hline $\begin{array}{l}\text { Garantizar un ambiente de trabajo saludable } \\
\text { y seguro. Gestionar riesgos de seguridad y } \\
\text { salud en en trabajo. }\end{array}$ & Estándares RSE & SA $8000: 2014$ & & & & & & & & $\mathrm{x}$ & $x$ & & $\begin{array}{l}\text { Aprendizaje y } \\
\text { crecimiento }\end{array}$ & Condición & C20 \\
\hline $\begin{array}{l}\text { Horario de trabajo acorde a la Ley. Días de } \\
\text { descanso }\end{array}$ & Estándares RSE & SA $8000: 2014$ & & & & & & & & $\mathrm{x}$ & $\mathrm{x}$ & & $\begin{array}{l}\text { Aprendizaje y } \\
\text { crecimiento }\end{array}$ & Condición & C20 \\
\hline $\begin{array}{l}\text { Valores, principios, estándares y normas de } \\
\text { conducta (GRI 102-16) }\end{array}$ & Estándares RSE & \begin{tabular}{|l|} 
Estándares GRI \\
$(2016)$
\end{tabular} & & & & & & $x$ & & & & & \begin{tabular}{|l|}
$\begin{array}{l}\text { Procesos } \\
\text { Internos }\end{array}$ \\
\end{tabular} & Condición & C14 \\
\hline $\begin{array}{l}\text { Consulta a grupos de interés sobre temas } \\
\text { económicos, ambientales y sociales (GRI } \\
\text { 102-21) }\end{array}$ & Estándares RSE & $\begin{array}{l}\text { Estándares GRI } \\
(2016)\end{array}$ & & & $x$ & $x$ & $x$ & $\mathrm{x}$ & & & & & $\begin{array}{l}\text { Procesos } \\
\text { Internos }\end{array}$ & Práctica & R7 \\
\hline $\begin{array}{l}\text { Sistema de gestión de la salud y la } \\
\text { seguridad en el trabajo. Cobertura del } \\
\text { siSGSST (GRI 403-1, 403-8) }\end{array}$ & Estándares RSE & $\begin{array}{l}\text { Estándares GRI } \\
(2016)\end{array}$ & & & & & & & & $\mathrm{x}$ & & & $\begin{array}{l}\text { Aprendizaje y } \\
\text { crecimiento }\end{array}$ & Práctica & R10 \\
\hline $\begin{array}{l}\text { Operaciones con participación de la } \\
\text { comunidad local, evaluaciones del impacto y } \\
\text { programas de desarrollo (GRI 413-1) }\end{array}$ & Estándares RSE & $\begin{array}{l}\text { Estándares GRI } \\
\text { (2016) }\end{array}$ & $\mathrm{x}$ & & & & $\mathrm{x}$ & & & & & & $\begin{array}{l}\text { Sostenibilidad } \\
\text { Financiera }\end{array}$ & Práctica & $\mathrm{R} 2$ \\
\hline $\begin{array}{l}\text { Nuevos proveedores que han pasado filtros } \\
\text { de selección de acuerdo con los criterios } \\
\text { sociales (GRI 414-1) }\end{array}$ & Estándares RSE & $\begin{array}{l}\text { Estándares GRI } \\
(2016)\end{array}$ & & & & & & & & & $\mathrm{x}$ & & $\begin{array}{l}\text { Procesos } \\
\text { Internos }\end{array}$ & Condición & C15 \\
\hline Independencia financiera: autofinanciación & Estándares RSE & \begin{tabular}{|l|} 
Balance del \\
Bien Común 5.0 \\
\end{tabular} & & & & & $\mathrm{x}$ & $x$ & & & & & $\begin{array}{l}\text { Sostenibilidad } \\
\text { Financiera }\end{array}$ & Objetivo & F4 \\
\hline $\begin{array}{l}\text { Financiación externa orientada al Bien } \\
\text { Común y Actitud ética de los proveedores } \\
\text { financieros }\end{array}$ & Estándares RSE & \begin{tabular}{|l|} 
Balance del \\
Bien Común 5.0
\end{tabular} & & & & & $\mathrm{x}$ & $\mathrm{x}$ & & & & & $\begin{array}{l}\text { Sostenibilidad } \\
\text { Financiera }\end{array}$ & Condición & C5 \\
\hline Impuestos y prestaciones sociales & Estándares RSE & \begin{tabular}{|l|} 
Balance del \\
Bien Común 5.0
\end{tabular} & & $x$ & $x$ & & & & & $x$ & & & $\begin{array}{l}\text { Sostenibilidad } \\
\text { Financiera }\end{array}$ & Condición & $\mathrm{C} 6$ \\
\hline $\begin{array}{l}\text { Participación del entorno social en la toma } \\
\text { de decisiones }\end{array}$ & Estándares RSE & \begin{tabular}{|l|} 
Balance del \\
Bien Común 5.0
\end{tabular} & $\mathrm{x}$ & $\mathrm{x}$ & $x$ & $\mathrm{x}$ & & & & & & & $\begin{array}{l}\text { Procesos } \\
\text { Internos }\end{array}$ & Condición & $\mathrm{C} 7$ \\
\hline \begin{tabular}{|l|} 
Mejorar cualificación profesional de los \\
potenciales trabajadores acorde a las \\
necesidades de los sectores económicos \\
\end{tabular} & $\begin{array}{l}\text { Estrategia } \\
\text { Organizaciones }\end{array}$ & $\begin{array}{l}\text { Servef (2014), } \\
\text { Alanna (2014) }\end{array}$ & $x$ & & & & & & & & & $\mathrm{x}$ & Social & Objetivo & S7 \\
\hline $\begin{array}{l}\text { Mejorar las oportunidades de empleo y } \\
\text { estructura del mercado }\end{array}$ & $\begin{array}{l}\text { Estrategia } \\
\text { Organizaciones }\end{array}$ & $\begin{array}{l}\text { Servef (2014), } \\
\text { Alanna (2014) }\end{array}$ & $\mathrm{x}$ & & $x$ & $\mathrm{x}$ & & & & & & & Social & Objetivo & S9 \\
\hline Desarrollar sus habilidades sociales & \begin{tabular}{|l|} 
Estrategia \\
Organizaciones
\end{tabular} & $\begin{array}{l}\text { Servef (2014), } \\
\text { Alanna (2014) }\end{array}$ & $\mathrm{x}$ & $x$ & & & & & & & & & Social & Objetivo & S7 \\
\hline Incrementar nivel de autoestima & $\begin{array}{l}\text { Estrategia } \\
\text { Organizaciones }\end{array}$ & $\begin{array}{l}\text { Servef (2014), } \\
\text { Alanna (2014) }\end{array}$ & $\mathrm{x}$ & & & & & & & & & & Social & Objetivo & S3 \\
\hline Fomento de la colaboración público - privada & $\begin{array}{l}\text { Estrategia } \\
\text { Organizaciones }\end{array}$ & $\begin{array}{l}\text { Servef (2014), } \\
\text { Alanna (2014) } \\
\end{array}$ & & & $\mathrm{x}$ & $x$ & $\mathrm{x}$ & & & & & & Social & Objetivo & S10 \\
\hline Diagnóstico de empleabilidad & $\begin{array}{l}\text { Estrategia } \\
\text { Organizaciones }\end{array}$ & $\begin{array}{l}\text { Servef (2014), } \\
\text { Alanna (2014) }\end{array}$ & $x$ & & & & & & & & & & \begin{tabular}{|l|} 
Procesos \\
Internos
\end{tabular} & Práctica & R6 \\
\hline $\begin{array}{l}\text { Mayor conocimiento de las necesidades del } \\
\text { mercado laboral a través de una estrecha } \\
\text { relación con empresas, clusters y academia }\end{array}$ & $\begin{array}{l}\text { Estrategia } \\
\text { Organizaciones }\end{array}$ & $\begin{array}{l}\text { Servef (2014), } \\
\text { Alanna (2014) }\end{array}$ & $\mathrm{x}$ & & & $\mathrm{x}$ & & & & & & $\mathrm{x}$ & $\begin{array}{l}\text { Procesos } \\
\text { Internos }\end{array}$ & Objetivo & P1 \\
\hline $\begin{array}{l}\text { Gestión coordinada y planificada de todos } \\
\text { los recursos }\end{array}$ & \begin{tabular}{|l|} 
Estrategia \\
Organizaciones
\end{tabular} & $\begin{array}{l}\text { Servef (2014), } \\
\text { Alanna (2014) }\end{array}$ & & & & & & $\mathrm{x}$ & & & & & \begin{tabular}{|l|} 
Sostenibilidad \\
Financiera
\end{tabular} & Objetivo & F3 \\
\hline $\begin{array}{l}\text { Estudiar posibles vías de financiación } \\
\text { innovadoras con capital privado }\end{array}$ & $\begin{array}{l}\text { Estrategia } \\
\text { Organizaciones }\end{array}$ & $\begin{array}{l}\text { Servef (2014), } \\
\text { Alanna (2014) }\end{array}$ & & & & & $x$ & $x$ & & & & & $\begin{array}{l}\text { Sostenibilidad } \\
\text { Financiera }\end{array}$ & Objetivo & F4 \\
\hline $\begin{array}{l}\text { Gestión clara y transparente de los recursos } \\
\text { en general }\end{array}$ & $\begin{array}{l}\text { Estrategia } \\
\text { Organizaciones }\end{array}$ & $\begin{array}{l}\text { Servef (2014), } \\
\text { Alanna (2014) }\end{array}$ & & $\mathrm{x}$ & $\mathrm{x}$ & & $\mathrm{x}$ & & & $\mathrm{x}$ & $\mathrm{x}$ & $x$ & $\begin{array}{l}\text { Procesos } \\
\text { Internos } \\
\end{array}$ & Condición & C16 \\
\hline
\end{tabular}

Nota: La columna "Cod. Mapa estratégico" se refiere a una codificación deliberada que contribuiría, posteriormente, a la diagramación del mapa estratégico (figura 3). Se construyeron conjuntos de criterios que aportaran a una misma perspectiva del mapa y, de acuerdo con la función que podrían desempeñar en el modelo (objetivo, condición o práctica), se clasificaron de la siguiente manera: los criterios considerados como "objetivos" de la perspectiva "social" se codifican con la letra "S"; los de la perspectiva "sostenibilidad financiera", con la letra "F"; los de la perspectiva "procesos internos" con la letra "P" y los de la perspectiva "Aprendizaje y crecimiento" con la letra "A". Todos los criterios considerados "condiciones" se codificaron con la letra "C" y los criterios considerados "prácticas" con la letra "R".

Fuente: Elaboración propia. 


\subsection{Bosquejo del mapa estratégico}

Seguido a la definición general de los criterios de gestión social, se procedió a diseñar una propuesta gráfica de un mapa estratégico para emprendimientos sociales de inclusión socio-laboral, puntualizando los elementos de la estrategia en cada una de sus perspectivas y estableciendo las "hipotéticas" relaciones causales entre los mismos. El propósito de este esquema fue brindar al estudio de caso, unos parámetros iniciales sobre los cuales se puede explorar las prácticas y acciones de los emprendimientos que contribuyen a la generación de valor en sus principales stakeholders.

Es de aclarar, que este mapa propone a manera de "guía" 27 objetivos estratégicos (ilustrados en los óvalos de la figura 3) potencialmente vinculables a los emprendimientos sociales, y alineados a los más relevantes criterios o requisitos de los estándares de RSE y de desarrollo sostenible. Es una herramienta flexible y adaptable a las organizaciones y, por tanto, uno de los productos finales que se espera obtener de esta investigación, es un mapa estratégico ajustado y/o complementado, en función de las particularidades de cada uno de los emprendimientos que se estudien.

Figura. 3. Mapa estratégico para emprendimientos sociales que trabajan por la inclusión socio-laboral.

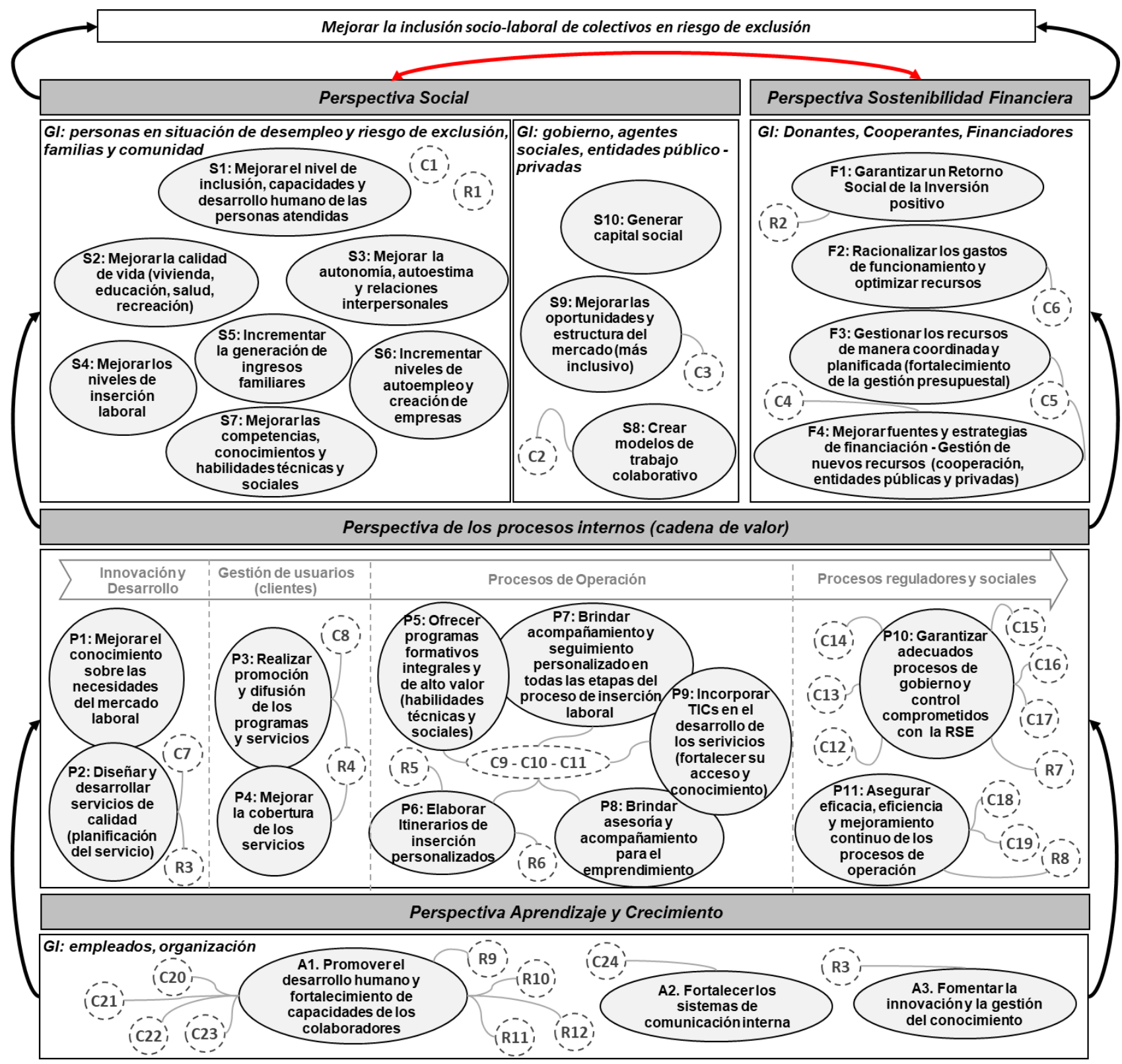

Nota: Los objetivos estratégicos se representan en los óvalos sombreados. Los objetivos sociales son categorizados con la letra S; los de sostenibilidad financiera, con la letra F; los de procesos internos, con la letra P y los de aprendizaje y crecimiento, con la letra A. Los círculos punteados con la letra " $C$ " se refieren a las condiciones de gestión mientras que los círculos punteados con la letra " $\mathrm{R}$ " representan las buenas prácticas para el logro de los objetivos. Las flechas sugieren las relaciones causales entre las perspectivas del mapa.

Fuente: Elaboración propia 
En la tabla 3, se describen 24 "condiciones de gestión" y 12 "buenas prácticas" asociadas a cada uno de los objetivos estratégicos y previamente ilustradas en el mapa estratégico. Todos estos criterios de gestión social se constituyen en el principal referente para determinar las necesidades puntuales de información del estudio de caso.

Tabla. 3. Condiciones de gestión y prácticas asociadas a cada objetivo estratégico

\begin{tabular}{|c|c|}
\hline Objetivos estratégicos & Condiciones (C) / Prácticas (R) \\
\hline \multicolumn{2}{|r|}{ Perspectiva Social } \\
\hline S1, S2, S3, S4, S5, S6, S7 & $\begin{array}{l}\text { C1: Impacto social positivo, medible y prolongado en el tiempo } \\
\text { R1: Definición de estrategias para el escalonamiento del impacto }\end{array}$ \\
\hline $\mathbf{S 8}$ & C2: Involucramiento de actores - Colaboración intersectorial \\
\hline S9 & $\begin{array}{l}\text { C3: Análisis de la coherencia entre la política económica de la localidad/región y las } \\
\text { necesidades del sector empresarial }\end{array}$ \\
\hline \multicolumn{2}{|r|}{ Perspectiva Sostenibilidad Financiera } \\
\hline F1 & R2: Realizar evaluación de impacto social \\
\hline F2 & C6: Pagos oportunos de impuestos, obligaciones y prestaciones sociales \\
\hline F3, F4 & $\begin{array}{l}\text { C4: Participación en política responsable (sin clientelismos) } \\
\text { C5: Uso de la banca solidaria, ética u orientada al bien común }\end{array}$ \\
\hline \multicolumn{2}{|r|}{ Perspectiva Procesos Internos } \\
\hline $\mathbf{P 2}$ & $\begin{array}{l}\text { C7: Participación activa de beneficiarios u otros grupos } \\
\text { R3: Implantación de estrategias de innovación }\end{array}$ \\
\hline P3, P4 & $\begin{array}{l}\text { C8: Información objetiva y transparente a los usuarios sobre los servicios, sus } \\
\text { características y condiciones } \\
\text { R4: Creación y mejora de canales para la comunicación }\end{array}$ \\
\hline P5, P6, P7, P8, P9 & $\begin{array}{l}\text { C9: Garantizar atención permanente al usuario. Gestión de quejas, peticiones, } \\
\text { denuncias y resolución de controversias } \\
\text { C10: Asegurar la protección y privacidad de los datos. } \\
\text { C11: Accesibilidad de los servicios (eliminación de barreras) } \\
\text { R5: Parametrización y segmentación de perfiles } \\
\text { R6: Diagnóstico de empleabilidad e "índice de idoneidad" }\end{array}$ \\
\hline \multirow[b]{2}{*}{ P10 } & $\begin{array}{l}\text { C12: Garantizar respeto por los derechos humanos y laborales } \\
\text { C13: Prevenir el deterioro del medio ambiente } \\
\text { C14: Definir normas de conducta. Fomentar prácticas anticorrupción y políticas para } \\
\text { gestión de conflictos de interés }\end{array}$ \\
\hline & $\begin{array}{l}\text { C15: Gestión responsable y ética de los proveedores } \\
\text { C16: Garantizar transparencia externa (rendición de cuentas) } \\
\text { C17: Implantar procesos para la gestión del riesgo } \\
\text { R7: Procesos de consulta a grupos de interés sobre temas económicos, ambientales y } \\
\text { sociales para la toma de decisiones }\end{array}$ \\
\hline P11 & $\begin{array}{l}\text { C18: Asegurar procesos de prestación del servicio donde se protege la salud, seguridad } \\
\text { e integridad de los usuarios } \\
\text { C19: Evaluación continua de los programas, planes y procesos } \\
\text { R8: Adoptar modelo de gestión por procesos (calidad) }\end{array}$ \\
\hline \multicolumn{2}{|r|}{ Perspectiva Aprendizaje y crecimiento } \\
\hline A1 & $\begin{array}{l}\text { C20: Garantizar condiciones de trabajo adecuadas (protección) } \\
\text { C21: Remuneración digna y justa } \\
\text { C22: Garantizar un adecuado clima laboral } \\
\text { C23: Garantizar personal debidamente calificado } \\
\text { R9: Promover programas de capacitación y desarrollo } \\
\text { R10: Sistema de gestión de seguridad y salud en el trabajo } \\
\text { R11: Planes de bienestar (conciliar la vida laboral y personal) } \\
\text { R12: Promover una cultura organizacional sostenible }\end{array}$ \\
\hline A2 & C24: Transparencia interna \\
\hline A3 & $\begin{array}{l}\text { R3: Implementación de estrategias de innovación aplicables a los productos/servicios, } \\
\text { procesos o métodos de la organización }\end{array}$ \\
\hline
\end{tabular}

Fuente: Elaboración propia

\subsection{Diseño del estudio de caso}

Dentro de esta última fase de la construcción metodológica, y considerando los insumos desarrollados en las etapas anteriores, se procedió entonces a diseñar un estudio de caso con el objetivo de identificar y analizar las formas de operación y las "buenas prácticas" de gestión utilizadas por los emprendimientos, en pro de 
garantizar el cumplimiento de sus objetivos estratégicos y su misión social (inclusión socio-laboral). Lo que, en otras palabras, significa la comprensión de las diversas estrategias, prácticas y procesos, por medio de los cuales, los emprendimientos sociales objeto de estudio, crean valor en sus principales stakeholders.

Al requerirse un importante nivel de profundización, tanto en la recolección como en el análisis de los datos, se optó por el estudio de casos como método de investigación, pues tal y como lo plantea Sumner y Tribe, este "comprende un número limitado de observaciones que aunque no son estadísticamente significativas, si permiten profundizar en la información recolectada a través de muestras cuidadosamente estructuradas" (2008:104).

Por tratarse de un trabajo enfocado en el "entendimiento y la interpretación" de las formas de operación de los emprendimientos sociales para la generación de valor y de las realidades y percepciones de sus grupos de interés, se encuentra que el estudio de caso es la técnica más adecuada, pues esta facilita el proceso de análisis y la comprensión de las características holísticas y significativas del comportamiento de pequeños grupos y de procesos organizacionales y gerenciales (Yin, 1994).

En el apartado siguiente se describe la metodología para llevar a cabo el estudio de casos propuesto y, paralelamente, se expone el avance en la aplicación de esta dentro de dos emprendimientos sociales valencianos que trabajan por la inclusión socio-laboral de colectivos en riesgo de exclusión.

\section{Resultados: estudio de caso para el análisis de las "buenas prácticas" de gestión organizacional que potencian la generación de valor social en los diferentes grupos de interés}

La estructura del estudio se abordó en siete pasos/etapas propuestas por los autores Villareal y Landeta (2010) y Luna y Rodriguez (2011), y las cuales se señalan en la figura 4. Paralelamente a la descripción de cada uno de los pasos, se ira detallando sobre los avances puntuales que, hasta ahora, se han obtenido en la aplicación de la metodología, usando para este último objetivo, recuadros de color gris.

Figura. 4. Abordaje metodológico del estudio de caso.

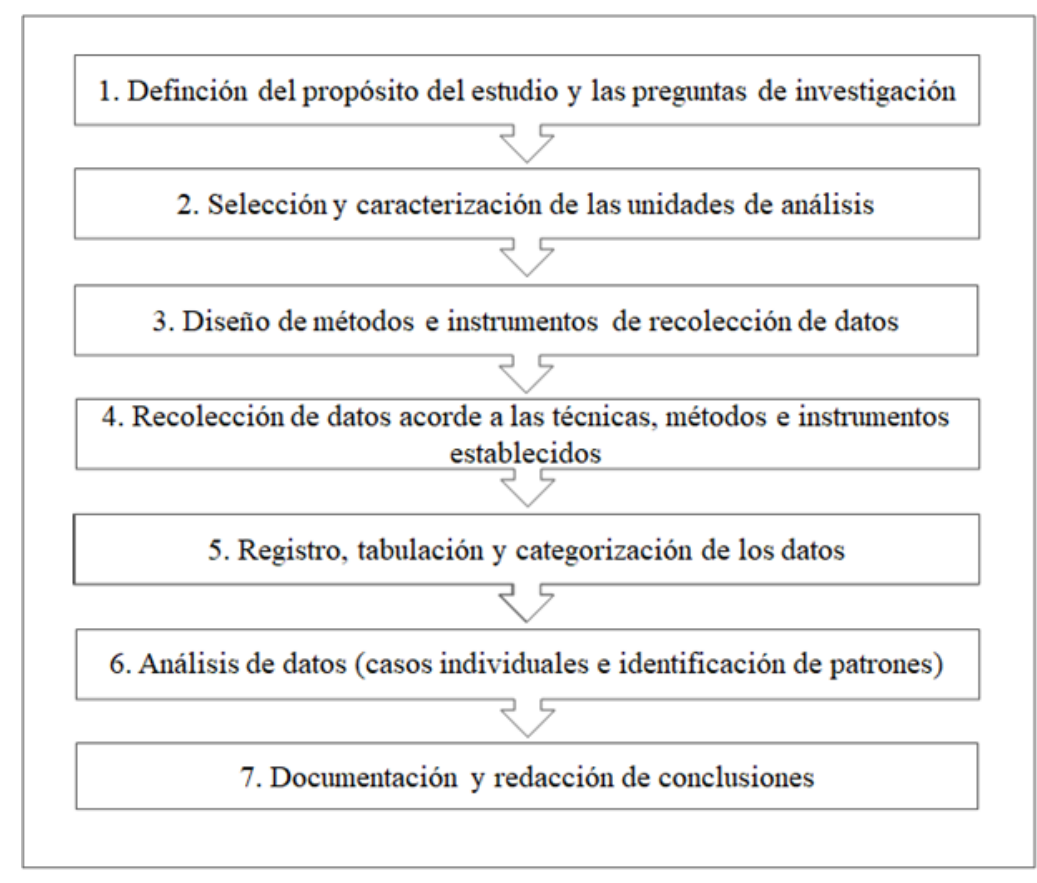

Fuente: Elaboración propia adaptado de Luna y Rodriguez (2011) y Villareal y Landeta (2010).

\subsection{Definición del propósito y las preguntas de investigación}

Como primer paso del estudio de caso resultó esencial concretar, tanto los objetivos, como las preguntas de investigación. Estas servirán de guía para focalizar la atención en lo que se quiere explorar (Castro, 2010) y, así, definir instrumentos de recolección de datos que revistan de efectividad el posterior trabajo de campo. Si bien en los apartados anteriores, de alguna manera, se ha abordado el propósito general de la investigación, en el cuadro 1 se precisan los objetivos (general y específicos) y en la tabla 4 se establecen las preguntas de investigación asociadas a los diferentes grupos de interés. 
Cuadro. 1. Definición de los objetivos del estudio de caso

\section{Objetivo general:}

Identificar y analizar las "buenas prácticas" organizacionales, por medio de las cuales, los emprendimientos sociales de inclusión socio-laboral generan o maximizan valor social en sus principales grupos de interés.

\section{Objetivos específicos:}

- Determinar las principales formas de "beneficio social o bienestar" percibidas por los usuarios, participantes y familias, como resultado de los servicios que reciben del emprendimiento social.

- Explorar sobre las redes colaborativas y otro tipo de sinergias intersectoriales que potencialmente pueden aportar al emprendimiento social para lograr maximizar su impacto.

- Analizar las más comunes y efectivas estrategias llevadas a cabo por el emprendimiento social para la captación de recursos y garantizar su sostenibilidad financiera.

- Identificar los modelos de servicios y procesos internos críticos desarrollados por los emprendimientos en el cumplimiento de su misión social.

- Evaluar de qué manera el emprendimiento social contribuye al desarrollo profesional y desarrollo humano de sus colaboradores y, por tanto, fortalece sus activos intangibles.

Fuente: Elaboración propia

Tabla. 4. Preguntas de investigación para el estudio de caso

\begin{tabular}{|c|c|c|c|c|c|c|c|}
\hline \multirow{2}{*}{ Perspectiva } & \multirow{2}{*}{ Pregunta de investigación } & \multicolumn{6}{|c|}{ Grupos de Interés } \\
\hline & & BEN & GOB & FIN & GER & EMP & PRO \\
\hline \multirow{2}{*}{ Social } & $\begin{array}{l}\text { ¿Cómo aporta el emprendimiento a la mejora de la calidad de vida } \\
\text { de sus beneficiarios, sus familias y, en general, al desarrollo de la } \\
\text { comunidad donde opera? }\end{array}$ & $X$ & $X$ & & & & \\
\hline & $\begin{array}{l}\text { ¿De qué forma, el emprendimiento social, se relaciona con el } \\
\text { Gobierno, la academia y otras organizaciones privadas y sociales } \\
\text { a fin de crear sinergias para la maximización del impacto social? }\end{array}$ & & $\mathrm{X}$ & & $\mathrm{X}$ & & \\
\hline \multirow{2}{*}{$\begin{array}{l}\text { Sostenibilidad } \\
\text { financiera }\end{array}$} & $\begin{array}{l}\text { ¿Cómo perciben los financiadores la relación entre el uso de los } \\
\text { recursos y el impacto social generado por el emprendimiento? }\end{array}$ & & $\mathrm{X}$ & $\mathrm{X}$ & $\mathrm{X}$ & & \\
\hline & $\begin{array}{l}\text { ¿Qué estrategias de sostenibilidad financiera puede adoptar el } \\
\text { emprendimiento en pro de maximizar su impacto social? }\end{array}$ & & & $X$ & $X$ & & \\
\hline \multirow{3}{*}{$\begin{array}{l}\text { Procesos } \\
\text { internos }\end{array}$} & $\begin{array}{l}\text { ¿Qué modelo de servicios (y actividades de valor crítico) debe } \\
\text { promover el emprendimiento en coherencia con su función social? }\end{array}$ & $X$ & & & $X$ & & \\
\hline & $\begin{array}{l}\text { ¿Qué procesos internos generan mayor valor y, por tanto, deben } \\
\text { fortalecerse para facilitar el logro de los objetivos sociales? }\end{array}$ & & & & $\mathrm{X}$ & & \\
\hline & $\begin{array}{l}\text { ¿Qué compromisos transversales deben asumirse en la cadena de } \\
\text { procesos a fin de garantizar un adecuado control, un buen } \\
\text { gobierno y evitar la generación de impactos negativos en los } \\
\text { stakeholders? }\end{array}$ & $\mathrm{X}$ & $\mathrm{X}$ & $\mathrm{X}$ & $\mathrm{X}$ & $\mathrm{X}$ & $\mathrm{X}$ \\
\hline \multirow{2}{*}{$\begin{array}{l}\text { Aprendizaje y } \\
\text { crecimiento }\end{array}$} & $\begin{array}{l}\text { ¿Cómo promover el aprendizaje y mejora continua del } \\
\text { emprendimiento por medio del capital humano y organizacional? }\end{array}$ & & & & $X$ & $X$ & \\
\hline & $\begin{array}{l}\text { ¿Cómo aporta el emprendimiento al desarrollo humano y } \\
\text { profesional de los equipos de trabajo? }\end{array}$ & & & & $\mathrm{X}$ & $\mathrm{X}$ & \\
\hline
\end{tabular}

Nota: BEN (Beneficiarios, Participantes, Familias); GOB (Gobierno, Agentes Sociales, Entidades público - privadas); FIN (Cooperantes, Donantes, Financiadores); GER (Gestores, Líderes y Gerentes del emprendimiento social); EMP (Empleados, Voluntarios y Colaboradores); PRO (Proveedores).

Fuente: Elaboración propia

\subsection{Selección de casos y caracterización de las unidades de análisis}

Después de aclarado el propósito del estudio y los objetivos específicos, el paso a seguir fue la definición y caracterización de las respectivas unidades de análisis, es decir, los individuos, grupos, entidades o instituciones, que se han de explorar y estudiar, a fin de dar respuesta a las preguntas planteadas. En este punto, es de suma importancia anotar que para dicha selección no se recurre a un muestro probabilístico, porque tal y como lo plantea Stake "la investigación con estudios de casos no es una investigación de muestras" (1998: 17). Para el presente trabajo resulta mucho más conveniente el uso de un muestreo intencional o selectivo donde "cada unidad - o conjunto de unidades - es cuidadosa e intencionalmente seleccionada por sus posibilidades de ofrecer información profunda y detallada sobre el asunto de interés para la investigación" (Martínez, 2012: 614). 
Con todo esto, y en coherencia a los objetivos establecidos, se decidió explorar y estudiar dos organizaciones sociales valencianas que trabajan en pro de la inclusión socio-laboral de colectivos vulnerables, las cuales se caracterizan en el cuadro 2. Asimismo, se establece los grupos de análisis en los que, posteriormente, se aplicarían los instrumentos de recolección de datos.

Cuadro. 2. Caracterización de los casos seleccionados y unidades de análisis

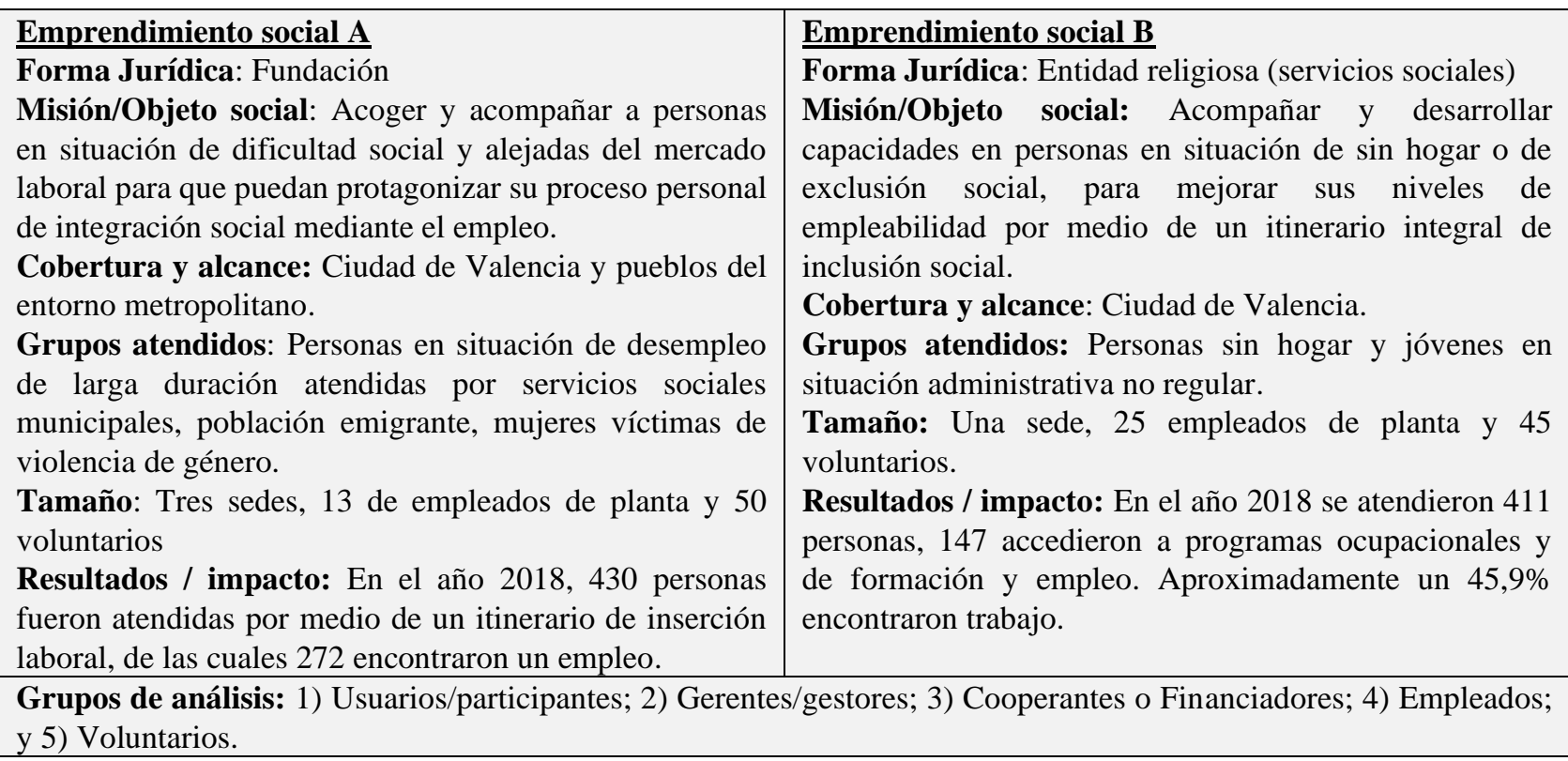

Fuente: Elaboración propia

\subsection{Diseño de instrumentos de recolección de datos}

Esta etapa, incluyó las actividades de diseño y construcción de los instrumentos de recolección de datos, para lo cual fue necesario, previamente, identificar y reconocer las principales "necesidades de información" y las posibles fuentes de datos. El mapa estratégico y los criterios de gestión social descritos en el apartado 3.3 de este documento fueron los principales insumos, para determinar esas necesidades particulares de información $\mathrm{y}$, por tanto, para definir el conjunto de preguntas a incluir en los instrumentos.

En el cuadro 3, se describen las técnicas e instrumentos de información establecidos para este estudio, en concordancia con las principales fuentes de información y los grupos de análisis. 
Cuadro. 3. Fuentes de información y técnicas de recolección de datos

\section{Descripción de fuentes y técnicas de recolección de datos}

\section{Fuente de información 1: Emprendimiento Social (Documentación estratégica)}

Técnica /Instrumentos: Análisis documental de la planificación estratégica, los reportes de rendición de cuentas o memorias de sostenibilidad, página Web y otros registros documentales de relevancia.

Tipo de información a recolectar: Estrategias, planes y acciones del emprendimiento, modelo de operación y de los servicios, resultados sociales e impacto, desempeño social y financiero, uso de los recursos, proyectos especiales, alianzas y trabajo en red.

Fuente de información 2: Emprendimiento Social (Patronos y miembros de la Alta Dirección)

Técnica /Instrumentos: Entrevista semiestructurada a miembro del patronato o de la Alta Dirección.

Tipo de información a recolectar: Aspectos filosóficos fundacionales, valores, gobernanza, estrategias sociales y de sostenibilidad financiera, manejo transparente de la información; visión a largo plazo y evaluación del impacto.

\section{Fuente de información 3: Emprendimiento Social (Líderes y Gestores)}

Técnica /Instrumentos: Entrevistas semiestructuradas a los líderes o gestores responsables de actividades críticas como: a) la prestación de servicios o ejecución de proyectos; b) la captación y administración de los recursos; c) la administración del recurso humano y el voluntariado y d) la comunicación estratégica.

Tipo de información a recolectar: Principales estrategias y resultados de los servicios/proyectos; actividades para el desarrollo del equipo de planta y voluntariado (desarrollo profesional y personal); administración de la información y la comunicación y relación con los grupos de interés.

\section{Fuente de información 4: Empleados y colaboradores del emprendimiento social}

Técnica /Instrumentos: Grupo focal equipo de empleados.

Tipo de información a recolectar: Percepción sobre el valor que les genera trabajar en la organización, prácticas que realiza el emprendimiento social por mejorar el bienestar laboral, conciliación con la vida familiar, remuneración digna, clima laboral, desarrollo profesional, etc.

\section{Fuente de información 5: Voluntarios del emprendimiento social}

Técnica /Instrumentos: Grupo focal equipo de voluntarios.

Tipo de información a recolectar: Percepción sobre el valor que les genera hacer voluntariado en la organización, prácticas que realiza la organización por contribuir a su desarrollo personal o profesional.

Fuente de información 6: Beneficiarios, usuarios o participantes del emprendimiento social

Técnica /Instrumentos: Grupo focal con beneficiarios directos del servicio, programa o proyecto.

Tipo de información a recolectar: Percepción sobre el servicio o acompañamiento recibido por parte de la organización (cómo perciben cambios en su vida a partir de este acompañamiento/servicio).

\section{Fuente de información 7: Financiadores o cooperantes del emprendimiento social}

Técnica /Instrumentos: Entrevista semiestructurada a un representante de un donante, cooperante o financiador.

Tipo de información a recolectar: Percepción sobre la generación de valor social que realiza la organización, criterios de auditoría y evaluación, reconocimiento de buenas prácticas de gestión para el impacto social.

Fuente: Elaboración propia

Como bien se puede observar, las técnicas de investigación propuestas fueron básicamente la entrevista semiestructurada, los grupos focales y la revisión documental. Así entonces, se definieron ocho guiones diferentes para ser utilizados en dichas entrevistas o grupos focales según el grupo de análisis y/o persona a entrevistar: a) director, presidente o gerente; b) líder de gestión humana; c) líder de comunicaciones y/o captación de fondos; d) líder o técnico de proyectos; e) empleados o colaboradores, f) voluntarios, g) beneficiarios, h) cooperantes o donantes. Estos guiones fueron adaptados en cada organización según su estructura específica y los roles particulares de cada cargo.

\subsection{Recolección de información y consideraciones éticas}

Finalizada la construcción de los instrumentos con base a las técnicas definidas, el siguiente paso de la metodología consiste en la recolección de datos (trabajo de campo). Esta etapa, tiene como principal fin reunir toda la información y evidencias necesarias que permitan, junto con un proceso riguroso de análisis, generar conclusiones que den cuenta sobre la estrategias y prácticas de los emprendimientos sociales para generar y maximizar valor social en sus stakeholders. 
Dentro de esta fase, también se incluyó la elaboración de un protocolo ético ${ }^{12}$ para ser aplicado previo a la recolección de datos. Dicho protocolo consta de dos documentos: el primero, un consentimiento informado, por medio del cual se comunica a cada entrevistado(a) o participante de un grupo focal, los objetivos, métodos de investigación y condiciones de tratamiento de los datos, entre otros aspectos. El segundo, un formato de acta que el participante voluntariamente firma aceptando las condiciones establecidas en el consentimiento informado.

En el cuadro 4, se describe el detalle de las actividades de recolección de datos realizadas en los dos emprendimientos sociales seleccionados y sus respectivos grupos de análisis.

Cuadro. 4. Aplicación instrumentos de recolección

Emprendimiento social A
- Cuatro entrevistas semiestructuradas (presidente,
gerente, líder de comunicaciones, orientadora
laboral).
- Tres grupos focales (miembros de la plantilla,
voluntarios y participantes/beneficiarios).
- Revisión y análisis de los documentos estratégicos:
a) Plan Estratégico 2016-2020, b) Memorias 2018, c)
Memorias 2017 y e) Manual del Empleado.
- Observación participante en la actividad "Dinámica
grupal de socialización de la estrategia de
comunicación".

Emprendimiento social B

- Cuatro entrevistas semiestructuradas (directora, coordinador de programas, líder de voluntarios, líder de comunicaciones).

- Tres grupos focales (miembros de la plantilla, voluntarios y beneficiarios).

- Revisión y análisis de los documentos estratégicos: a) Política y objetivos de calidad 2018, b) Memorias 2018 y c) Memorias 2017.

Cooperante/Donante (transversal a los dos emprendimientos):

Se realizó una entrevista a un representante de la Obra Social La Caixa (Gestor Territorial de la Ciudad de Valencia).

Fuente: Elaboración propia

\subsection{Registro, análisis e interpretación}

El análisis de datos es, quizás, la actividad más crítica y compleja en el desarrollo del estudio de casos; pues de un buen análisis dependerá la generación de conclusiones de valor que den respuesta a las preguntas de investigación, y la calidad de este, también está sujeta a un apropiado proceso de tabulación y clasificación de los datos recolectados.

La aplicación de los instrumentos propuestos genera, indudablemente, gran cantidad de datos cualitativos, que requieren ser examinados sistemáticamente a fin de comprender qué dicen estos frente a los objetivos de estudio. Si bien, este proceso de análisis e interpretación debe ser asumido directamente por el investigador (pues difícilmente un programa estadístico o herramienta suple completamente esta tarea analítica y crítica), se puede hacer uso de herramientas que faciliten la visualización y proporcionen un ambiente de lectura detallada y profunda (Kalman \& Rendón, 2016).

Para este estudio de caso, se diseñó un instrumento de registro y análisis de datos usando una hoja de cálculo. Dicha herramienta, tal y como se ilustra en la tabla 5, permite relacionar y clasificar todos los datos recolectados en diferentes categorías según las perspectivas del mapa estratégico y sus objetivos. De esta manera, se facilita el registro de las ideas más relevantes y su posterior localización para un mejor proceso de lectura y análisis.

12 El protocolo ético se elaboró considerando los lineamientos de la Política de Integridad Científica y Buenas Prácticas en Investigación de la Universidad Politécnica de Valencia (2012). El consentimiento informado utilizado, y previamente validado por el Director de tesis doctoral asociada al presente estudio, incluyó los siguientes aspectos: a) información sobre los objetivos del estudio; b) descripción de los métodos de recolección de datos (entrevista semiestructurada y grupos focales); c) explicación sobre la "voluntariedad" en la participación y la renuncia a la misma en cualquier momento del estudio; d) aclaración con relación a que el estudio no contempla ninguna compensación económica ni beneficio directo para los participantes y e) descripción de los términos en los cuales se usaran los datos (confidencialidad, anonimato y conservación). 
Tabla. 5. Extracto herramienta de tabulación y análisis de datos (perspectiva de procesos internos)

\begin{tabular}{|c|c|c|c|c|c|c|c|c|c|c|c|c|c|c|c|c|}
\hline \multirow[b]{2}{*}{ 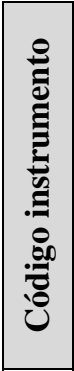 } & \multirow[b]{2}{*}{ 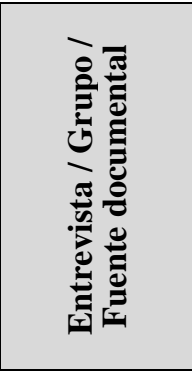 } & \multirow[b]{2}{*}{ 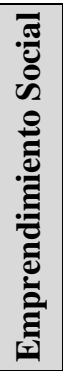 } & \multirow[b]{2}{*}{ 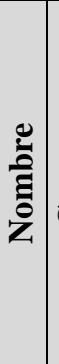 } & \multirow{2}{*}{\multicolumn{2}{|c|}{ 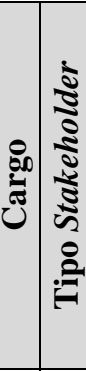 }} & \multicolumn{11}{|c|}{$\begin{array}{l}\text { Objetivos estratégicos, prácticas y condiciones PERSPECTIVA PROCESOS } \\
\text { INTERNOS }\end{array}$} \\
\hline & & & & & & 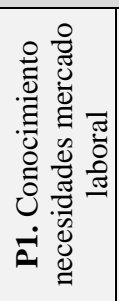 & 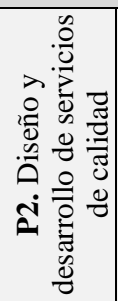 & 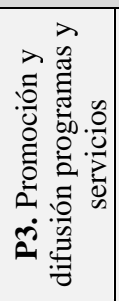 & 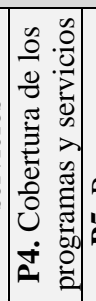 & 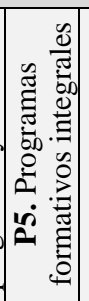 & 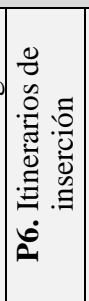 & 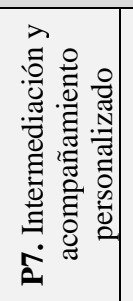 & 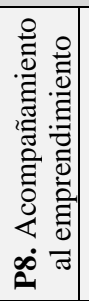 & 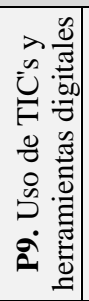 & 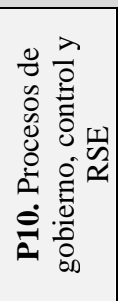 & 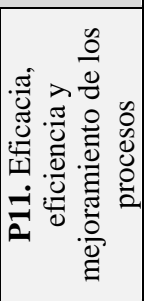 \\
\hline D1. & Documento 1 & A & & & & & & & & & & & & & & \\
\hline D2. & Documento 2 & $\mathrm{~A}$ & & & & & & & & & & & & & & \\
\hline E1. & Entrevista 1 & B & & & & & & & & & & & & & & \\
\hline E2. & Entrevista 2 & $\mathrm{~A}$ & & & & & & & & & & & & & & \\
\hline G1. & Grupo focal 1 & $\mathrm{~B}$ & & & & & & & & & & & & & & \\
\hline G2. & Grupo focal 2 & $\mathrm{~B}$ & & & & & & & & & & & & & & \\
\hline O1. & Observación 1 & $\mathrm{~A}$ & & & & & & & & & & & & & & \\
\hline
\end{tabular}

Fuente: Elaboración propia

Aunque la herramienta de tabulación y análisis está diseñada para registrar la información recolectada en ambos emprendimientos (A y B), el análisis, inicialmente, requiere realizarse de manera individual con el fin de identificar las "prácticas propias" de cada organización. Posteriormente, y no menos importante, se procede a realizar una comparación de los casos, para así, identificar patrones, convergencias y divergencias. A partir de estos análisis (individual y comparado), se dará forma a las conclusiones que deberán responder nuestras preguntas de investigación

\subsection{Generación de conclusiones y documentación}

La documentación y redacción del informe de estudio de caso son el cierre de la metodología propuesta y el producto que contendrá las conclusiones, de acuerdo con los objetivos trazados. Luna y Rodriguez (2011) sugieren, que independientemente de la forma que se le dé al informe final, existen unos pasos o etapas para la construcción de este: a) definir la audiencia del informe; b) elaborar la estructura y c) solicitar una revisión a peers, expertos o a personas que hayan participado del estudio. Atendiendo estas sugerencias, se define un breve protocolo y estructura para la elaboración del informe final, el cual se detalla en el cuadro 5. 
Cuadro. 5. Protocolo y estructura del informe final del estudio de caso

\section{Estructura y contenido del informe final de resultados}

\section{Definición de la audiencia}

- Gerentes, líderes y gestores de las organizaciones sociales estudiadas.

- Gerentes, líderes y gestores de otras organizaciones y emprendimientos sociales con interés en el tema de estudio.

- Académicos e investigadores en el tema de estudio.

\section{Estructura del informe}

Se propone la siguiente estructura en concordancia con los objetivos y preguntas de investigación, y en el marco de las perspectivas del mapa estratégico, modelo base del estudio:

i. Descripción y contexto de los emprendimientos sociales estudiados (elementos fundacionales, misión, caracterización, estructura y órganos de gobierno).

ii. El mapa estratégico de los emprendimientos sociales estudiados.

iii. La perspectiva social: ¿cómo genera valor el emprendimiento para los grupos de personas atendidas, sus familias y la comunidad en general?

iv. La perspectiva de sostenibilidad financiera: ¿Cuáles estrategias resultan exitosas en los emprendimientos sociales para mejorar las fuentes de financiación y garantizar su sostenibilidad en el tiempo?

v. La perspectiva de procesos internos: ¿Qué servicios, actividades y prácticas se destacan dentro de la cadena de valor de los emprendimientos por su mayor contribución al impacto social en sus stakeholders internos y externos?

vi. La perspectiva de aprendizaje y crecimiento: ¿Cuáles son las principales iniciativas y estrategias de los emprendimientos para promover el desarrollo profesional y humano de sus equipos?

vii. Monitoreo, seguimiento y evaluación de las estrategias para la generación de valor.

viii. Conclusiones finales y recomendaciones.

\section{Revisión y validación}

Antes de proceder con la diseminación del informe final del estudio, se presentará a los gerentes/representantes de los emprendimientos estudiados, a fin de validar y obtener realimentación sobre los hallazgos preliminares. Adicionalmente, se propone presentar el trabajo a dos "expertos temáticos" que validen tanto la metodología, la redacción y la misma fiabilidad de los hallazgos.

\section{Medios de difusión}

Con la previa y debida autorización de los emprendimientos sociales estudiados, se pretende difundir los resultados del estudio de caso por medio de una publicación formal (paper).

Fuente: Elaboración propia

\section{Reflexiones finales y conclusiones}

La metodología producto de este trabajo actualmente se encuentra en proceso de implementación. Por tanto, se propone un conjunto de reflexiones o conclusiones preliminares en dos líneas: a) frente al mapa estratégico base de la propuesta metodológica y b) frente a los avances en la aplicación del estudio de caso y posibles mejoras a la metodología.

\subsection{Frente al mapa estratégico base de la propuesta metodológica}

La metodología objeto de este trabajo sienta sus bases en la adaptación del modelo de mapa estratégico propuesta por Murillo (2020). Este modelo, sugiere que la generación de valor en un emprendimiento social se da en diferentes vías. En primer lugar, puede afirmarse, que se crea valor social para los stakeholders externos (beneficiarios, familias, comunidad, financiadores, etc) a partir del mismo cumplimiento de la misión social y, para lo cual, se requiere de una gestión eficiente de los recursos y de unos procesos internos adecuados, eficaces y "responsables" según las necesidades y expectativas de todos los grupos de interés.

Por otro lado, el emprendimiento también puede generar valor dentro de sus stakeholders internos (empleados, voluntarios, gerentes, etc). El fortalecimiento del capital humano y organizacional (activos intangibles), conlleva cambios relevantes positivos, tanto para los colaboradores, como para la misma organización. Esto, a su vez, redundará en una mejor gestión de los procesos internos que potencializa la capacidad del emprendimiento para generar impacto social en los stakehoders externos.

La creación de valor social también está condicionada al cumplimiento o gestión de unos criterios mínimos que garanticen que las acciones de la organización realmente aportan al desarrollo sostenible y que no vayan en detrimento o contravía de las demandas legítimas provenientes de los grupos de interés (incluido 
el medio ambiente). Es así, que además de desarrollar una propuesta de valor orientada a la misión social (modelo de servicios y procesos internos), el emprendimiento debe comprometerse con unas actuaciones básicas y unos mínimos de "desempeño" en coherencia con las necesidades y expectativas de los diferentes stakeholders.

Consecuente a esto, el mapa estratégico base del estudio de caso propone, tanto un conjunto de objetivos estratégicos y prácticas de gestión que pueden ser transversales a los emprendimientos de inclusión sociolaboral, como una serie de "condiciones mínimas" que deben ser consideradas por la organización a fin de evitar la "destrucción de valor" en alguno de los grupos de interés. Estos elementos, denominados criterios de gestión social y clasificados en las cuatro perspectivas del mapa (social; de sostenibilidad financiera; de procesos internos y de aprendizaje y crecimiento), se definieron tras un exhaustivo análisis de los principios, asuntos o requisitos contenidos en reconocidos estándares de RSE y modelos de desarrollo.

Es preciso mencionar, que tanto los modelos de desempeño social y de desarrollo analizados, como la documentación estratégica de dos organizaciones de empleo inclusivo valencianas (SERVEF y Alanna) realizaron una importante contribución al bosquejo del mapa estratégico. Por citar algunos ejemplos: a) dentro del el enfoque de desarrollo sostenible se examinaron 21 criterios, de los cuales, 14 aportaron a la definición de los "objetivos sociales"; b) el 70\% de los criterios analizados de los diferentes estándares de RSE dieron lugar a la definición de las "condiciones de gestión" dentro de las perspectivas de procesos internos y de aprendizaje y crecimiento; c) los objetivos de sostenibilidad financiera, se definieron con base a las prioridades estratégicas de las organizaciones y a requisitos de desempeño propuestos por el Balance del bien común 5.0 y los estándares GRI y d) de los 61 elementos estratégicos propuestos por las organizaciones, nueve aportaron a los "objetivos sociales", seis a los objetivos de "aprendizaje y crecimiento" y 17 a los objetivos de "procesos internos".

Es así entonces, que los criterios de gestión social se vuelven los pilares para la definición de las fuentes de información y la construcción de los instrumentos de recolección de datos en nuestro estudio de caso. Todos estos elementos, de alguna manera, fueron abordados dentro de los mismos guiones de entrevista, grupos focales e, incluso, en la herramienta de clasificación y análisis de información. Tal y como se detalla en la tabla 6, cada uno de los criterios de gestión social contenidos en el mapa estratégico se asocian a las preguntas de investigación que se pretenden resolver. En la medida en que se logre obtener información sobre cómo las organizaciones abordan o asumen estos objetivos, condiciones y prácticas, podremos acercarnos a algunas respuestas y avanzar en la comprensión de aquellos enfoques y modelos que utilizan los emprendimientos en favor de la creación y maximización del valor social.

Tabla. 6. Criterios de gestión social asociados a las preguntas de investigación

\begin{tabular}{|c|c|c|c|c|}
\hline \multirow{2}{*}{$\begin{array}{l}\text { Perspectiva } \\
\text { mapa } \\
\text { estratégico }\end{array}$} & \multirow[b]{2}{*}{ Pregunta de investigación } & \multicolumn{3}{|c|}{ Criterios de gestión social } \\
\hline & & $\begin{array}{l}\text { Objetivos } \\
\text { estratégicos }\end{array}$ & $\begin{array}{l}\text { Condiciones } \\
\text { de gestión }\end{array}$ & Prácticas \\
\hline \multirow[b]{2}{*}{ Social } & $\begin{array}{l}\text { ¿Cómo aporta el emprendimiento a la mejora de la calidad de } \\
\text { vida de sus beneficiarios, sus familias y, en general, al } \\
\text { desarrollo de la comunidad donde opera? }\end{array}$ & $\begin{array}{l}\text { S1, S2, S3, } \\
\text { S4, S5. S6, } \\
\text { S7 }\end{array}$ & & \\
\hline & $\begin{array}{l}\text { ¿De qué forma, el emprendimiento social, se relaciona con el } \\
\text { Gobierno, la academia y otras organizaciones privadas y } \\
\text { sociales a fin de crear sinergias para la maximización del } \\
\text { impacto social? }\end{array}$ & $\mathrm{S} 8, \mathrm{~S} 9, \mathrm{~S} 10$ & $\mathrm{C} 1, \mathrm{C} 2, \mathrm{C} 3$ & \\
\hline \multirow{2}{*}{$\begin{array}{l}\text { Sostenibilidad } \\
\text { financiera }\end{array}$} & $\begin{array}{l}\text { ¿Cómo perciben los financiadores la relación entre el uso de los } \\
\text { recursos y el impacto social generado por el emprendimiento? }\end{array}$ & $\mathrm{F} 1$ & & $\mathrm{R} 1, \mathrm{R} 2$ \\
\hline & $\begin{array}{l}\text { ¿Qué estrategias de sostenibilidad financiera puede adoptar el } \\
\text { emprendimiento en pro de maximizar su impacto social? }\end{array}$ & $\mathrm{F} 2, \mathrm{~F} 3, \mathrm{~F} 4$ & C4, C5, C6 & \\
\hline \multirow{3}{*}{$\begin{array}{l}\text { Procesos } \\
\text { internos }\end{array}$} & $\begin{array}{l}\text { ¿Qué procesos internos generan mayor valor y, por tanto, deben } \\
\text { fortalecerse para facilitar el logro de los objetivos sociales? }\end{array}$ & $\begin{array}{l}\text { P1, P3, P4, } \\
\text { P9, P11 }\end{array}$ & $\mathrm{C} 7, \mathrm{C} 8$ & $\begin{array}{l}\text { R3, R4, } \\
\text { R5 }\end{array}$ \\
\hline & $\begin{array}{l}\text { ¿Qué modelo de servicios (actividades de valor crítico) debe } \\
\text { promover el emprendimiento en coherencia con su función } \\
\text { social? }\end{array}$ & $\begin{array}{c}\mathrm{P} 2, \mathrm{P} 5, \mathrm{P} 6 \\
\text { P7, P8 }\end{array}$ & $\begin{array}{l}\text { C9, C10, } \\
\text { C11, C18 }\end{array}$ & R6 \\
\hline & $\begin{array}{l}\text { ¿Qué compromisos transversales deben asumirse en la cadena } \\
\text { de procesos a fin de garantizar un adecuado control, un buen } \\
\text { gobierno y evitar la generación de impactos negativos en } \\
\text { cualquiera de los stakeholders? }\end{array}$ & P10 & $\begin{array}{l}\text { C12, C13, } \\
\text { C14, C15, } \\
\text { C16, C17, } \\
\quad \text { C19 }\end{array}$ & $\mathrm{R} 7, \mathrm{R} 8$ \\
\hline \multirow{2}{*}{$\begin{array}{l}\text { Aprendizaje y } \\
\text { crecimiento }\end{array}$} & $\begin{array}{l}\text { ¿Cómo promover el aprendizaje y } \\
\text { emprendimiento por medora } \\
\text { organizacional? }\end{array}$ & $\mathrm{A} 2, \mathrm{~A} 3$ & $\mathrm{C} 24$ & R3, R12 \\
\hline & $\begin{array}{l}\text { ¿Cómo aporta el emprendimiento al desarrollo humano y } \\
\text { profesional de los equipos de trabajo? }\end{array}$ & A1 & $\begin{array}{l}\mathrm{C} 20, \mathrm{C} 21 \\
\mathrm{C} 22, \mathrm{C} 24\end{array}$ & $\begin{array}{l}\text { R9, R10, } \\
\quad \text { R11 }\end{array}$ \\
\hline
\end{tabular}

Fuente: Elaboración propia 


\subsection{Frente a los avances en la aplicación del estudio de caso}

La estructuración del estudio de caso, usando un conjunto de etapas secuenciales, ha permitido organización y rigurosidad en la investigación. Con la experiencia obtenida hasta el momento en la aplicación de la metodología, se han detectado aciertos, pero también algunas oportunidades de mejora que podrán ser abordadas a fin de revestir el trabajo de mayor fiabilidad y solidez de sus resultados.

En primer lugar, y frente a la selección de los "grupos de análisis", no fueron incluidos para la recolección de datos algunos stakeholders como los proveedores y/o representantes de la Administración, Gobierno o Empresa Privada-Social. En lo que se ha avanzado del trabajo, se ha podido evidenciar fuertes vínculos y redes de trabajo colaborativo de los emprendimientos, tanto con entidades oficiales, como con empresas privadas. Por lo anterior, sería recomendable agregar estos stakeholders a los "grupos de análisis" y plantear una técnica de recolección de datos (entrevista o grupo focal) a uno o más representantes de los mismos, pues está siendo evidente que de este tipo de sinergias e interacciones surgen importantes contribuciones al desarrollo y a la generación de impacto.

Durante el trabajo de campo, se ha precisado flexibilizar las técnicas y herramientas de recolección de datos. Ante las diferentes estructuras organizacionales y los disímiles roles de los cargos/posiciones dentro de los emprendimientos sociales estudiados, se hizo necesario modificar (personalizar) los guiones de entrevista, especialmente, para los gerentes, gestores y líderes de los emprendimientos. Asimismo, se llevó a cabo otra técnica adicional en uno de los emprendimientos que no estaba contemplada dentro del diseño inicial del estudio, Para el caso del emprendimiento A, se tuvo la oportunidad de participar en una dinámica interna de socialización con todos los colaboradores y voluntarios, por lo cual, fue oportuno aplicar una observación participante, de la cual se logró extraer valiosa información para los objetivos de la investigación.

Otro elemento que fue omitido en el diseño metodológico, y que podría ser abordado con mayor profundidad en posteriores aplicaciones, se refiere a la identificación y tratamiento de los posibles sesgos en la recolección de datos. Dicho riesgo se hizo más evidente, especialmente en los grupos focales que se llevaron a cabo con participantes/usuarios de los emprendimientos. Si bien, en dichas sesiones las preguntas fueron planteadas de manera abierta y cuidadosa, las características de los grupos, las diferentes personalidades y experiencias particulares de los individuos participantes, provocaron, en numerosas ocasiones, conflictos y discusiones divagantes que se alejaban de los temas en cuestión.

En aras de resolver la dispersión en un grupo en particular (emprendimiento A), se acudió a solicitar la presencia de una Orientadora/Formadora (profesional vinculada a la organización) y, aunque se logró enfocar nuevamente a los participantes en las temáticas centrales de discusión, la presencia de Orientadora, pudo haber acarreado la obtención de respuestas no sinceras o fieles a la realidad. El riesgo de los sesgos, el cual es más latente en investigaciones cualitativas de este corte, puede ser contemplado desde el mismo diseño metodológico. En este caso, para evitar la situación anteriormente descrita, los grupos focales de este tipo, podrían ser acompañados por un profesional experto (de la rama de la sicología o sociología) externo la organización. Así, se garantizaría un manejo adecuado de las situaciones/conflictos que se puedan generar dentro del grupo y, por tanto, una recolección de información más completa y objetiva.

En la etapa de tabulación y análisis de datos, también se han encontrado posibles "inconsistencias" en la información recolectada, de aquí la relevancia de realizar adecuados procesos de triangulación y comparación. Específicamente, este tipo de inconveniente se detecta al cotejar los datos obtenidos de la "revisión documental" versus los datos de las entrevistas y grupos focales. No siempre es coincidente las proposiciones de un Plan Estratégico, por ejemplo, con las realidades expuestas por los miembros o participantes del emprendimiento. En este sentido, es de vital importancia la capacidad analítica e interpretativa del investigador, a fin de que pueda comprender las causas de dichas incoherencias y determinar hasta qué punto pueden verse afectados los resultados de la investigación.

De acuerdo con lo que hasta ahora se ha avanzado, podría concluirse que el estudio de caso diseñado con base al mapa estratégico (y sus criterios de gestión de social), han permito explorar, identificar y analizar, las acciones, estrategias y prácticas que implementan los emprendimientos y que contribuyen a la creación de valor social en sus stakeholders internos y externos. Si bien se ha encontrado que no todo el conjunto de criterios establecidos en el mapa aplica en su totalidad a las dos organizaciones estudiadas, a partir de ellos, si se ha podido identificar elementos que nos acercan a las respuestas de las preguntas establecidas para esta investigación, en lo que se refiere a las formas, prácticas y estrategias por medio de las cuales, el emprendimiento de inclusión socio-laboral, genera impacto en el territorio donde opera.

Por último, mencionar, que una vez se finalice la etapa de "documentación y generación de conclusiones" del estudio de caso, tal y como se describe en el apartado 4.6, se procederá a realizar un ejercicio de presentación y validación de los resultados. Dicha actividad se reviste de alta importancia, pues además de abrir un espacio de realimentación con las mismas organizaciones, sentará una base para el análisis y 
discusión de un potencial modelo de gestión ${ }^{13}$ que pueda ser adaptado e implementado por otros emprendimientos y organizaciones sociales de carácter similar.

\section{Referencias Bibliográficas}

AECID. (2017) Estudio sobre la contribución de la empresa a la agenda de los objetivos de desarrollo sostenible (ODS). Recuperado de http://www.aecid.es/Centro-Documentacion/default.aspx.

Albasu, J., \& Nyameh, J. (2017) Relevance of Stakeholders Theory, Organizational Identity Theory and Social Exchange Theory to Corporate Social Responsibility and Employees Performance in the Commercial Banks in Nigeria. International Journal of Business, Economics and Management, 4(5), pp. 95-105. https://doi.org/10.18488/journal.62.2017.45.95.105.

Asociación Alanna. (2014) Memoria de actividades Alanna 2014. Recuperado de http://alanna.org.es.s231151.furanet.com/wp-content/uploads/2016/01/Memoria-Actividades-actualizado-a-2014.pdf.

Austin, J., Gutierrez, R., Ogliastri, E., \& Reficco, E. (2006) Gestión efectiva de emprendimientos sociales: lecciones extraídas de empresas y organizaciones de la sociedad civil en Iberoamérica. Washington, DC: Banco Interamericano de Desarrollo.

Austin, J., Stevenson, H., \& Wei-Skillern, J. (2006) Social and Commercial Entrepreneurship: Same, Different, or Both? Entrepreneurship Theory and Practice, 30(1), pp. 1-22.

Blachfellner, M., Drosg-Plöckinger, A., Fieber, S., Hofielen, G., Knakrügge, L., Kofranek, M., ... Teriete, M. (2017) Manual del Balance del Bien Común 5.0. Recuperado de https://economiadelbiencomun.org.

Buckland, H., \& Murillo, D. (2014) La Innovación Social en América Latina. Marco conceptual y agentes. Instituto de Innovación Social de ESADE y Fondo Multilateral de Inversiones (Banco Interamericano de Desarrollo).

Bugg-Levine, A., \& Emerson, J. (2011) Impact Investing: Transforming How We Make Money while Making a Difference. Innovations: Technology, Governance, Globalization, 6(3), pp. 9-18.

Castro, E. (2010) El estudio de casos como metodologá de investigación y su importancia en la dirección y administración de empresas. Revista Nacional de Administración, 1(2), pp. 31-54. https://doi.org/10.1016/S11352523(12)60033-1.

Comisión Europea. (2011) Comunicación de la Comisión al Parlamento Europeo, al Consejo, Comité Económico y Social Europeo y al Comité de las Regiones. Estrategia renovada de la UE para 2011-2014 sobre la responsabilidad social de las empresas, (25 Octubre 2011, COM(2011) 681 final). Recuperada de https://eur-lex.europa.eu/legalcontent/ES/TXT/PDF/?uri=CELEX:52011DC0681\&from=EN.

Cortina, A. (2009) Ética de la empresa: No sólo Responsabilidad Social. Revista Portuguesa de Filosofía, pp. 113-127.

Curto, M. (2012) Los Emprendedores Sociales: innovación al servicio del cambio social. Cuadernos de La Cátedra "La Caixa" de Responsabilidad Social de La Empresa y Gobierno Corporativo, (13).

Dees, J. G. (1998) The Meaning of Social Entrepreneurship. Recuperada de https://centers.fuqua.duke.edu/case/wpcontent/uploads/sites/7/2015/03/Article_Dees_MeaningofSocialEntrepreneurship_2001.pdf.

Defourny, J., \& Nyssens, M. (2008) Social enterprise in Europe: recent trends and developments. Social Enterprise Journal, 4(3), pp. 202-228. https://doi.org/10.1108/17508610810922703.

Duque, Y., Cardona, M., \& Rendón, J. (2013) Responsabilidad Social Empresarial: Teorías, índices, estándares y certificaciones. Cuadernos de Administración Universidad Del Valle, 29(50), pp. 196-207.

Elkington, J. (2013) Enter the triple bottom line. In The Triple Bottom Line: Does it All Add Up (Vol. 1, pp. 23-38). Routledge.

Emerson, J. (2003) The Blended Value Proposition: Integrating Social and Financial Returns. California Management Review, 45(4), pp. 34-51.

European Commission. (2014) A map of social enterprises and their eco-systems in Europe. Executive Summary. Recuperado de https://ec.europa.eu/social/BlobServlet?docId=12987\&langId=en.

European Commission. (2021) Internal Market, Industry, Entrepreneurship and SMEs. Recuperado de https://ec.europa.eu/growth/sectors/social-economy/enterprises_en.

Flores, J. Z. (2016) Medición de valor social: el método del Retorno Social de Inversión (SROI). InnovaG, (1), pp. 4952. https://doi.org/10.1017/CBO9781107415324.004.

Freeman, R. E., \& Reed, D. L. (1983) Stockholders and Stakeholders: A New Perspective on Corporate Governance. California Management Review, 25(3), pp. 88-106.

González, E. (2017) Perspectiva de los grupos de interés en la RSE. In Responsabilidad, ética y sostenibilidad empresarial (Primera Ed, pp. 87-99). Pearson Education.

GRI. (2018) GRI Standards. Recuperado de https://www.globalreporting.org/standards/.

GRI, Pacto Global de las Naciones Unidas, \& WBCSD. (2016) SDG Compass. La guía para la acción empresarial en los ODS. Recuperado de https://sdgcompass.org/wp-content/uploads/2016/06/SDG_Compass_Spanish-one-pagerview.pdf.

13 Para efectos de este trabajo el concepto modelo de gestión hace referencia a un marco de planificación estratégica (conjunto de lineamientos, políticas, objetivos, procesos, prácticas, etc), que facilita a la organización el cumplimiento de su misión social y la maximización de su contribución al desarrollo sostenible (social, económico y ambiental). 
Harold, J., Spitzer, J., \& Emerson, J. (2007) Blended Value Investing: Integrating enviromental risks and opportunities into securities valuation. Recuperado de https://www.sbs.ox.ac.uk/sites/default/files/2019-10/pdf-integratingvaluation-risk-securities.pdf.

Ibarra-Baidón, C. (2019) Emprendimiento social y responsabilidad social corporativa: prospectiva y elementos distintivos. Revista Administración Contemporánea . Revista de Investigación, (37).

Kalman, J., \& Rendón, V. (2016) Uso de la hoja de cálculo para analizar datos cualitativos. Magis, Revista Internacional de Investigación En Educación, 9(18), pp. https://doi.org/http://dx.doi.org/10.11144/Javeriana.m9-18.uhca.

Kaplan, R., \& Norton, D. (2004) Mapas Estratégicos: convirtiendo los activos intangibles en resultados tangibles. Barcelona: Gestión 2000.

Luna, E., \& Rodriguez, L. (2011) Pautas para la elaboración de estudios de caso. Sector Conocimiento y AprendizajeBID-Vicepresidencia de Sectores y Conocimiento. Recuperado de https://publications.iadb.org/handle/11319/6434.

Maguregui Urionabarrenechea, M. L., Corral Lage, J., \& Elechiguerra Arrizabalaga, C. (2018) La identificación de los grupos de interés de las entidades sin fines de lucro en la emisión de información transparente. REVESCO. Revista de Estudios Cooperativos, Segundo Cuatrimestre, No 131, pp. 65-85. https://doi.org/10.5209/REVE.62814.

Mair, J., \& Martí, I. (2006) Social entrepreneurship research: A source of explanation, prediction, and delight. Journal of World Business, 41(1), pp. 36-44. https://doi.org/10.1016/j.jwb.2005.09.002.

Mitchell, R. K., Agle, B. R., \& Wood, D. J. (1997) Toward a Theory of Stakeholder Identification and Salience : Defining the Principle of Who and What Really. Academy of Management Review, 22(4), pp. 853-886.

Mulgan, G. (2010) Measuring Social Value. Stanford Social Innovation Review, 8(3), pp. 38-43.

Muñoz-Martin, J. (2013) Ética empresarial , Responsabilidad Social Corporativa (RSC) y Creación de Valor Compartido (CVC). Globalización, Competitividad y Gobernabilidad, 7(13), pp. 76-88. https://doi.org/10.3232/GCG.2013.V7.N3.05.

Murillo, L. M. (2016) Diseño de un Cuadro de Mando Integral para la Gestión del Impacto Social de Entidades y Proyectos Sociales Orientados al Incremento del Nivel de Empleabilidad de Colectivos en Riesgo de Exclusión. Universidad Politécnica de Valencia. Recuperado de https://riunet.upv.es/handle/10251/67786.

Murillo, L. M. (2020) Cuadro de mando integral para la gestión del impacto social en organizaciones de empleo inclusivo. CIRIEC-España, Revista de Economía Pública, Social y Cooperativa, No 98, pp. $153-188$. https://doi.org/107203/CIRIEC-E.98.13368.

Naciones Unidas. (2009) El Pacto Mundial de las Naciones Unidas. Civismo empresarial en la economía mundial. Recuperado de https://www.unido.org/sites/default/files/2010-11/GC_Brochure_Spanish_0.PDF.

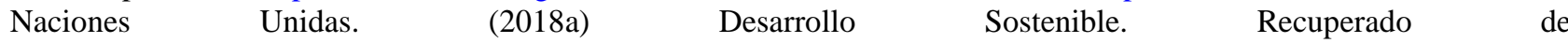
http://www.un.org/es/ga/president/65/issues/sustdev.shtml.

Naciones Unidas. (2018b) La Agenda 2030 y los Objetivos de Desarrollo Sostenible: una oportunidad para América Latina y el Caribe. Publicación de las Naciones Unidas. Santiago.

Narrillos, H. (2012) ECONOMIA SOCIAL: Valoración y medición de la inversión social (método SROI). Madrid: Ecobook.

Nicholls, A. (2009) We do good things, don't we?: Blended Value Accounting in social entrepreneurship. Accounting, Organizations and Society, 34(6-7), pp. 755-769. https://doi.org/10.1016/j.aos.2009.04.008.

Nicholls, J., Lawlor, E., Neitzer, E., \& Goodspeed, T. (2012) A guide to Social Return on Investment. Recuperado de http://www.socialvalueuk.org/resources/sroi-guide/.

Organización Internacional de Normalización (ISO). (2010) Norma Internacional ISO 26000. Guía de Responsabilidad Social. Traducción oficial. Recuperado de https://www.iso.org/obp/ui\#iso:std:iso:26000:ed-1:v1:es.

Parlamento Europeo. (2014) Directiva 2014/95/UE del Parlamento Europeo y del Consejo, de 22 de octubre de 2014, por la que se modifica la Directiva 2013/34/UE en lo que respecta a la divulgación de información no financiera e información sobre diversidad por parte de determinadas g. Diario Oficial de La Unión Europea. Serie L, (330, 15 noviembre), pp. 1-9.

Porter, M., \& Kramer, M. (2011) La creación de valor compartido. Harvard Business Review América Latina, EneroFebr, 1-18.

Retolaza, J. L., San-Jose, L., \& Ruiz, M. (2010) Hacia un replanteamiento de la teoría de stakeholder: cuatro propuestas innovadoras.

Rubio, F. J. (2006) La exclusión socio-laboral de colectivos con dificultades en su acceso al mercado laboral. Nómadas. Revista Crítica de Ciecias Sociales y Jurídicas, 14(2). Recuperado de http://www.redalyc.org/articulo.oa?id=18153297011.

Sánchez Espada, J., Martín López, S., Bel Durán, P., \& Lejarriaga Pérez de las Vacas, G. (2018) Educación y formación en emprendimiento social: características y creación de valor social sostenible en proyectos de emprendimiento social. REVESCO. Revista de Estudios Cooperativos, Tercer Cuatrimestre, $\mathrm{N}^{\mathrm{o}}$ 129, pp. 16-38. https://doi.org/10.5209/REVE.62492.

Slaper, T. F., \& Hall, T. J. (2011) The Triple Bottom Line: What Is It and How Does It Work? Indiana Business Review, 86(1), $\quad$ pp. $\quad 4-8 . \quad$ Recuperado de http://search.proquest.com/openview/068e4b4e0245b339afe0358602df3830/1?pq-origsite=gscholar.

Social Accountability International. (2014) Norma Internacional Responsabilidad Social. SA8000:2014.

Social Value UK. (2018) What is the social value? Recuperado de http://www.socialvalueuk.org/what-is-social-value/. 
Strandberg, L. (2010) La medición y la comunicación de la RSE: indicadores y normas. Cuadernos de La Cátedra "La Caixa” de Responsabilidad Social de La Empresa y Gobierno Corporativo, (9).

Sumner, A., \& Tribe, M. (2008) International Development Studies: Theories and Methods in Research and Practice (Vol. 1). Los Angeles: SAGE. https://doi.org/10.4135/9781446279397.

United Nations. (2020) World youth report: Youth Social Entrepreneurship and the Agenda 2030. https://www.un.org/development/desa/youth/wp-content/uploads/sites/21/2020/07/2020-World-Youth-ReportFULL-FINAL.pdf.

Universidad Politécnica de Valencia. (2012) Política de integridad científica y buenas prácticas en investigación en la Universitat Politécnica de Valencia. Recuperado de http://www.upv.es/entidades/VIIT/info/708238normalc.html.

Villareal, O., \& Landeta, J. (2010) El Estudio de Casos como Metodología de Investigación Científica en Dirección y Economía de la Empresas. Investigaciones Europeas de Dirección y Economía de La Empresa, 16(3), pp. 31-52. Recuperado de https://dialnet.unirioja.es/servlet/articulo?codigo=3304962.

Yin, R. K. (1994) Case study research: design \& methods. Applied Social Research Methods Series, 5.

Yunus, M. (2010) Building social business: The new kind of capitalism that serves humanity's most pressing needs. New York: Public Affairs. 